\title{
STATISTICAL DISCRIMINATION IN A COMPETITIVE LABOR MARKET
}

\author{
Jonathan B. Berk
}

Working Paper 6871

http://www.nber.org/papers/w6871

\section{NATIONAL BUREAU OF ECONOMIC RESEARCH \\ 1050 Massachusetts Avenue \\ Cambridge, MA 02138 \\ January 1999}

The author would like to Peter DeMarzo, Murray Carlson, Burton Hollifield, Barbara Spencer, Raman Uppal, Ivo Welch and Joe Williams for their insights and comments, and Virginia Le for providing research assistance. The views expressed here are those of the author and do not reflect those of the National Bureau of Economic Research.

(1) 1998 by Jonathan B. Berk. All rights reserved. Short sections of text, not to exceed two paragraphs, may be quoted without explicit permission provided that full credit, including $(\bullet$ notice, is given to the source. 
Statistical Discrimination in a Competitive Labor Market

Jonathan B. Berk

NBER Working Paper No. 6871

January 1999

\section{ABSTRACT}

This paper studies the effect of employee job selection in a model of statistical discrimination in a competitive labor market. In an economy in which there are quality differences between groups, a surprisingly strong condition is required to guarantee discrimination against the worse qualified group --- MLRP must hold. In addition, because of the self-selection bias induced by competition, the resulting discrimination is small when compared to the magnitude of the underlying quality differences between groups. In cases in which the discrimination results because employers' ability to measure qualifications differs from one group to another, the conditions under which one group is discriminated against are much weaker. In general, the group employers know least about is always favored. The economic impact of discrimination that is derived from quality differences between groups is shown to be quite different to the economic impact of discrimination that derives from differences in employer familiarity between groups. In the latter case, for a set of equally qualified employees, it is possible for members of the group that is discriminated against to have higher wages. Finally, we show how the results can be used to explain a number of empirical puzzles that are documented in the literature.

Jonathan B. Berk

Haas School of Business

University of California, Berkeley

545 Student Services

Berkeley, CA 94720-1900

and NBER

berk@haas.berkeley.edu 


\section{Introduction}

There is perhaps no social issue more controversial than the perceived persistence of "unfair" discrimination in the economy. This type of discrimination occurs when a characteristic, such as race, that an applicant has no control over and that has no direct bearing on the ability of the applicant to perform the duties she is applying to do, is used as a criterion for selecting the applicant. Thus, although an employee's sex or race might have no more influence on his ability to do a particular job than, say, the color of her eyes, there are examples of economies in which employers base their hiring decisions, in part, on an applicant's race or sex. The question of how this practice can persist in a competitive market has intrigued economists for some time.

The first complete economic analysis of discrimination is by Becker (1971). In this study Becker takes a taste for discrimination as an economic primitive. However, as Arrow (1972, p. 86) subsequently argued:

"The possible channels by which discriminatory attitudes come to affect wages are well stated by Becker, but what might be termed the general equilibrium aspects are largely ignored; that is, the effects of wage differentials on the stimulation of compensating behavior are slighted, and, as will be seen, these create a crucial dilemma for an appreciation of the value of economic theory."

Arrow goes on to point out that in a general equilibrium, a taste for discrimination should be competed away. In response to his own argument Arrow presents a number of possible origins of discrimination that would not be competed way in a general equilibrium. Perhaps the most important is his theory of how statistical discrimination might arise in the economy. If one assumes that assessing the quality of a potential employee is costly, an employer is likely to look for costless ways to asses quality. Under these circumstances, if observing an employee's race is costless and the employer has prior beliefs about how different race groups are qualified, then it is "immediately obvious that if the subjective probability on the mind of an employer that a white worker is qualified is higher than a black worker is qualified, there will have to be a wage difference if the employer is to hire any blacks at all (Arrow (1972, p. 97))."

Although Arrow's argument is convincing, we will argue in this paper that it cannot be used to conclude that if one group is better qualified, on average, than another group, then the latter group will necessarily be discriminated against. Consequently, the argument that this selection mechanism reduces incentives for self improvement (see Akerlof (1976)) is not necessarily true. Before either statement can be made another general equilibrium aspect of the problem, arguably at least as important as competition amongst firms, namely, the competition amongst employees for jobs, must be considered. 
The purpose of this paper is to study the effect of employee job selection on statistical discrimination in a competitive market. To understand why this may be important, consider the decision problem faced by a person who wishes to apply for a job at a firm that she knows discriminates against the population group to which she belongs. If she still chooses to apply for the job she must rationally believe that her chances of being hired warrant spending the effort to go through the application process. Since she is discriminated against, this means that her qualifications for the job must be good enough so that she stands a chance of being hired despite the discrimination. In other words, to get the job she will have to be better qualified than she would have to be in the absence of the discriminatory policy. If the original reason for the discrimination derives from differences in average qualifications across population groups, this self-selection bias will act to neutralize these differences.

There are two distinct notions of statistical discrimination in the literature. The first, which we will term "qualification" discrimination, results from qualification differences between groups. The other notion, which we will term "measurement" discrimination results from differences in the ability of employers to access quality in different population groups rather than differences in the distribution of quality within the groups. From a public policy perspective, it is important to understand when every member of a group will suffer from discrimination, hereafter, systematic discrimination. The initial focus of this paper is to derive conditions that result in systematic discrimination in a model that includes employee competition.

The conditions that provide systematic discrimination in an economy with qualification differences between groups are surprisingly strong. We demonstrate that even the distribution of quality in one group stochastically dominates the other group, systematic discrimination might not result. Indeed, it is possible to construct an example of such an economy in which there is no discrimination whatsoever. We show that a sufficient condition for systematic discrimination is that the monotone likelihood ratio property holds for the two quality distributions.

In general it is quite possible that for certain jobs the discrimination can favor the group that is, on average, worse qualified. To see, intuitively, how this might happen, note that an employer's prior distribution of applicant quality is derived from the distribution of quality of only the agents who would choose to apply for the job. While one group may be better overall, this ranking could well be reversed in the subset of agents who choose to apply for the job.

Quite different results obtain when the distribution of skills is the same for both groups, but employers are better able to access skill level in one group. If attention is restricted to economies in which the offered wage in any job is no more than twice the wage in the next best job, then systematic discrimination will always result and it will favor members of 
the group that employers are less familiar with. Besides being somewhat counter-intuitive, this result contrasts with inferences from models in which competition amongst employees is not modeled explicitly.

The paper also studies the interrelation between qualification and measurement discrimination. We argue that when both factors are present in the economy, the latter is more influential than the former. This allows us to generate a number of seemingly pathological cases of economies in which the overall quality distribution of the "better" group stochastically dominates the "worse" group and employers are better able to measure quality in the "better" group, yet in every job in the economy, employers choose to statistically discriminate against members of the "better" group.

The notion of discrimination we have implicitly used up to now is what we term "legal" discrimination - different criteria are used to evaluate candidates from different groups. The paper also studies another notion of discrimination, what we term "economic" discrimination. This type of discrimination measures economic differences between agents of the same quality but from different groups. We show that the interrelation between these two distinct notions of discrimination is far from intuitive. When the driving factor is quality differences between groups, we show that systematic legal discrimination results in systematic economic discrimination. Surprisingly, this is not the case when employers' differences in accessing quality is the driving factor. Systematic legal discrimination need not result in systematic economic discrimination. In a number of cases we show that members of one group can simultaneously benefit from economic discrimination but still be legally discriminated against. This result has important legal implications because the US Supreme Court has ruled that evidence of economic discrimination can be admissible in cases alleging legal discrimination. ${ }^{1}$

These theoretical results might also help explain a number of empirical puzzles. One example, first documented by Kuhn (1987), is the finding that the amount of measured economic discrimination is inversely related to the probability that an employee will report being discriminated against. Another is Neal and Johnson's (1996) finding that even when there are large differences in prior skill levels, evidence of statistical is hard to detect. What evidence they do find in some shows that the economic discrimination favors the worse qualified group.

Although the focus of this paper is on criteria that employees have no control over, there is no a priori reason why the results should be limited to these measures. One particularly interesting application that we do not explicitly consider is the choice of which university to attend. Two important inferences in this paper are that the discrimination that results from qualification differences is small relative to these differences, and that under measurement

\footnotetext{
${ }^{1}$ International Association of Firefighters v. Cleveland. 1986; Sheet Metal Workers v. Equal Employment Opportunity Commission, 1986.
} 
discrimination the less familiar group is likely to be favored. It is therefore not clear that the signal that a job candidate graduated from a top university, per se, confers much advantage. Indeed, one might argue, based on the inferences in this paper, that for weak candidates, if two universities have graduates with similar skill levels, attending the lesser known university might confer an advantage.

The rest of the paper is organized as follows. The next section reviews the literature on statistical discrimination. Section 3 presents the model. In Section 4 we derive sufficient conditions that provide systematic discrimination as a result of both quality differences and differences in employers' ability to measure quality in two population groups. We then derive the welfare implications of such discrimination. Section 5 illustrates the relative importance of qualification and measurement discrimination in the context of three special cases. In Section 6 we argue, in the context of two empirical studies, that the results can help to explain a number of empirical puzzles that have been documented. The final section concludes by considering the some implications of the results. All proofs and a number of the more technical lemmas can be found in the appendix.

\section{Statistical Discrimination}

There are (at least) two distinct definitions of discrimination that are used in the literature. The first is what we will refer to as legal discrimination because it derives from the legal definition of discrimination in the United States and Canada. Under the laws of the United States or Canada, any employer who uses race, sex, religion, age or nationality as a criterion to make a decision is guilty of discrimination. ${ }^{2}$ Thus the legal definition is based simply on whether a certain predefined set of characteristics are used in a personnel decision. Although it is often presumed that the result of such an act of discrimination will economically disadvantage one group, the law itself makes no reference to the effect of the act of discrimination.

The second definition of discrimination, which we will refer to as economic discrimination, defines discrimination in terms of economic differences between population groups. In this paper we define an equilibrium that features economic discrimination as one in which the average wage of two otherwise identical population groups that differ in only one of these predefined characteristics is not the same. An example would be an equilibrium in which the average wages of equally qualified men and women differ. Note that this definition of discrimination makes no reference to why such an inequality exists.

Although the introduction highlights one of Arrow's theories of discrimination, it would be misleading to leave the impression that Arrow was alone in proposing this theory. McCall

\footnotetext{
${ }^{2}$ See, in the U.S., Title VII of the Civil Rights Act (42 U.S.C., s. 2000e) of 1964 and in Canada, the Canadian Human Rights Act 1976-77, c. 33, s. 1.
} 
(1973), Phelps (1972), Reder (1972) and Spence (1973) all published similar hypotheses around the same time. As Akerlof (1976) also argues, rational employers will use factors such as race and sex in their hiring decisions whenever they cannot measure applicants' qualities perfectly. Employers use their prior knowledge of the distribution of these factors in the economy to Bayesian update their estimate of the quality of each applicant. This updating, since it uses measures that an applicant has no control over, acts to reduce the incentive of applicants to invest in self-improving technologies. Thus quality differences between population groups are reinforced. Average wages will be lower among the group of applicants that have lower average quality and if two applicants that appear equally qualified apply for the same job, the employer picks the applicant from the better group.

The subsequent literature on statistical discrimination addresses two reasons why employer's priors may differ between groups. First, an employer may statistically discriminate because she knows that the distribution of qualifications within groups differ. We will henceforth refer to statistical discrimination that results for this reason as qualification discrimination. Second, the distribution of qualifications within the groups may be identical, however, the employer's ability to measure these qualifications may differ. Statistical discrimination that results for this reason will be referred to as measurement discrimination. Aigner and Cain (1977) conclude that qualification discrimination always leads to discrimination in favor of the better qualified group while the results for measurement discrimination are ambiguous. In the latter case, above (below) average members of the better (lesser) known group are favored.

Lundberg and Startz (1983) postulate that measurement discrimination by itself could lead to qualification discrimination. In their model, "dagger" workers productivity is observed with greater error then "star" workers. This implies a lower return for education for dagger workers compared to star workers. Consequently, dagger's, are on average, worse qualified and so employers use this information to discriminate. In that model equally qualified dagger workers are paid less than their star counterparts. A notable exception occurs for very low skilled jobs - the above argument is reversed. We will demonstrate that this seemingly pathological case is in fact the general case in a model in which employee competition is modeled explicitly.

Cornell and Welch (1996) consider what the pool of workers will look like at company hiring highly skilled labor in the presence of measurement discrimination. They find that the group that has less measurement error is favored. This implies that more of these workers are hired. Cornell and Welch argue that since same group agents are more likely to be better at evaluating each other, this selection is reinforcing. Ultimately, the probability that the work force of the company consists of anything but the better measured group is extremely low. As we will show, it is not clear this will persist in an economy in which 
employee competition is explicitly modeled.

The empirical literature documenting race and sex discrimination is extensive. ${ }^{3}$ The most common approach, first used by Oaxaca (1973), regresses wages on human capital variables like education level, job tenure, age, etc. that are intended to control for innate differences in skill levels. The residual of this regression is used as the measure of economic discrimination. Another approach uses a score on a standardized test to control for skill levels. ${ }^{4}$ Both of these approaches yield qualitatively similar results — by controlling for skill level wage differences are substantially reduced. Furthermore, this wage difference has declined steadily so the most recent studies actually find no difference at all.

These results pose somewhat of a puzzle for theories of statistical discrimination that do not explicitly model employee competition, because a concomitant decrease in skill differences has not been detected. These models imply that skill differences should result in statistical discrimination. One of the interesting implications of explicitly modeling employee competition is that skill differences do not necessarily result in statistical discrimination.

\section{The Model}

\subsection{Primitives}

Consider an economy with a set of agents each of whom is characterized by her marginal productivity in each job offered. For ease of exposition we will refer to this marginal product as an agent's quality. Agents are separated into two types (i.e., race or sex group), $h$ and $l$. There are $N_{l}$ agents of type $l$ and $N_{h}$ agents of type $h$. Each agent of type $t$ has true quality, $q \in Q_{t} \subseteq Q$, where $Q$ is the set of all possible quality levels. Let the probability measure $F^{t}(q)$ on $Q$ be the probability of randomly selecting an agent with quality $q$ or less out of the population of agents of type $t . F^{t}$ is assumed to be absolutely continuous with respect to a $\sigma$-finite measure $\mu$ on $Q$ with Radon-Nikodym derivative (density function) $f^{t}$. A distinguishing characteristic of the agent types is that the distribution of agents' true quality may differ between the two types, that is, $F^{h}(q) \neq F^{l}(q)$.

There are a set of employers in the economy each of whom advertise that they have a job available requiring a certain specific quality level and paying a fixed wage. For simplicity, we will assume that each applicant can only apply to one job. ${ }^{5}$ When an applicant applies for

\footnotetext{
${ }^{3} \mathrm{~A}$ complete review of this literature is beyond the scope of this paper. The interested reader can consult Cain (1986) and Sorensen (1990) for surveys of the literature on estimating wage discrimination between race and gender groups. Two examples of more recent studies are Oaxaca (1994) and Macpherson and Hirsch (1995).

${ }^{4}$ see Curtright (1973), O'Neill (1990) and Neal and Johnson (1996)

${ }^{5}$ Although it might appear, at first glance, that the results may be sensitive to this assumption, the model's qualitative implications remain valid when employees can apply to multiple jobs. The reason is that implicitly lowering the cost of applying for a job by giving employees the opportunity to apply to multiple
} 
a job, an employer costlessly observes the agent's type. She can then further investigate the quality of the applicant by, for example, looking over the applicant's resume, interviewing the applicant and calling the applicant's references. Since this investigation is costly, it is assumed that it is not economically feasible for the employer to determine the applicant's true quality perfectly. Thus, employers do not observe agents' true quality $q$ directly, rather they observe a noisy signal on the true quality $s \equiv q+\delta$, where $\delta \in\left[-\Delta_{t}, \Delta_{t}\right]$ has a mean-zero distribution function, $G^{t}(\cdot)$, that may depend on the applicant's type but is independent of the quality of the applicant. Denote $g^{t}(\cdot)$ as the density function corresponding to $G^{t}$ (i.e., $\left.G^{t \prime}(\cdot)=g^{t}(\cdot)\right)$. The signal $s$ should be thought of as the employer's estimation of the applicants qualifications for the job before she uses her prior knowledge of the distribution of quality. It should be interpreted as what under the law is referred to as an applicant's "qualifications" for the job.

We will assume that for all $t, g^{t}(\cdot)$ is symmetric and logconcave (see An (1998) for a formal definition and characterization of this class of density functions). Logconcavity is desirable because this class is known be broad $^{6}$ (see Bagnoli and Bergstrom (1989)) and the assumption guarantees, amongst other things, that an employer's estimate of quality is increasing in the signal. There are a number of useful results that are known about logconcave density functions. Lemma A.1, in the appendix, summarizes the ones needed in this context.

There are $I$ different sectors of the economy. In each sector, $i, i=1 \ldots I$, there are $n_{i}$ available jobs all advertising the same wage, $w_{i}$, and requiring the same minimum quality level. ${ }^{7}$ Given this wage structure, employees choose to apply to a job in the sector that provides the highest expected wage and employers in that sector hire any applicant whose expected marginal product (quality) exceeds $b_{i} \cdot{ }^{8}$ Without loss of generality we will assume that wages are monotonicaly ranked in the sectors, that is, for every $i, w_{i}>w_{i+1}$.

Finally, we will assume that the support of $F^{t}(\cdot)$, for $t=l, h$, is such that there is always a positive probability of finding agents of both types who have such low quality they are unable to get any job. In this case they can apply for and get an unskilled job with certainty. This job requires no qualifications and pays a wage $w_{I+1}=1$. We will henceforth

jobs decreases the self selection only if the optimal response of employers is ignored. In fact what happens is that employers anticipate that the lower application cost will result in more unqualified applicants and so they raise the hiring standard. This reduces the incentive for unqualified applicants to apply and so the self selection bias remains important. This is explicitly demonstrated in Berk (1998), were an extension of the model that allows multiple applications in different sectors is derived.

${ }^{6}$ The fact that $\delta$ is bounded does not restrict this class because any truncation of a logconcave distribution is still logconcave.

${ }^{7}$ This assumption is motivated by Mortensen (1973) (see also Lippman and McCall (1976)) where it is shown that in a model with multiple job markets, that a single wage will prevail on each market.

${ }^{8}$ This assumption is motivated by Lippman and McCall (1976) who show that in a model in which employers search sequentially for employees, the optimal hiring policy is to hire any employee whose marginal product exceeds some lower bound. 
refer to this wage (job) as the reservation wage (job) in the economy.

\subsection{Equilibrium}

We first compute, $B_{t}(s, a, b)$, an employer's expectation of quality upon observing a signal $s$ from an agent of type $t$, given that for that type of agent, only agents of quality $q \in[a, b)$ apply for the job. Let $E_{t}[\cdot]$ denote the expectation under the probability measure $F^{t}$. The employer's expectation of the quality of an applicant of type $t$ when he observes a signal $s$ is:

$$
\begin{aligned}
B_{t}(s, a, b) \equiv E_{t}[q \mid s, q \in(a, b]] & =\int_{a}^{b} u g^{t}(s-u) d H^{t}(u ; s, a, b) \\
& =\left(\frac{1}{\int_{a}^{b} g^{t}(s-u) d F^{t}(u)}\right) \int_{a}^{b} u^{t}(s-u) d F^{t}(u),
\end{aligned}
$$

where,

$$
d H^{t}(u ; s, a, b) \equiv\left(\frac{1}{\int_{a}^{b} g^{t}(s-u) d F^{t}(u)}\right) d F^{t}(u) .
$$

The next lemma shows that employers' expectations of quality are increasing in the signal realization.

Lemma 3.1 For any fixed $a, b$ with $0<a<b$ and any $s, \frac{\partial B_{t}(s, a, b)}{\partial s} \geq 0$.

The lemma shows that when employers know that the quality of agents who apply for their jobs lie between two bounds, their expectation of an agent's quality, given a signal realization $s$, is weakly increasing in $s$. Consequently, there will exist a critical signal such that an applicant is hired if and only if her signal exceeds the critical signal. Since such a signal will exist for each job, $i$, as well, potentially, for each employee type, $t$, it will henceforth be denoted $s_{t i}^{*}$. It remains to be shown that if employers adopt this hiring policy employees will self select so that the quality of agents who apply for their jobs lie between two bounds.

Agents have the following decision problem. Faced with a menu of possible jobs with wages $w_{i}, i=1 \ldots I+1$, each agent maximizes her expected wage by choosing which job to apply for. An agent that is successful in getting the job he applied for is paid the wage $w_{i}$, otherwise he is paid nothing. Formally, agents of type $t$ solve the following problem:

$$
\max _{i} E\left[w_{i}\right]=\max _{i} w_{i} P_{t}(q, i)
$$

where $P_{t}(q, i)$ is the probability that an agent of type $t$ and quality $q$ will get the $i^{\text {th }}$ job if he applies for it. If agents in this model have rational expectations, then their perceived 
probability of getting the $i^{\text {th }}$ job must turn out to be their actual probability of landing the job, that is, for any agent of type $t$ and quality $q$,

$$
\begin{aligned}
P_{t}(q, i) & =\mathbf{P}\left[q+\delta \geq s_{t i}^{*}\right] \\
& =\mathbf{P}\left[\delta \geq s_{t i}^{*}-q\right] \\
& =1-G^{t}\left(s_{t i}^{*}-q\right) .
\end{aligned}
$$

We will henceforth assume the if an agent is indifferent between applying for any two jobs, he always applies for the job with the higher wage.

Lemma 3.2 If an agent of type $t$ and quality $q$ chooses to apply for the $i^{\text {th }}$ job, then all agents of type $t$ with quality less than $q$ will choose to apply for a job with $j \geq i$ (i.e., they will either choose to apply for the same job or a job with a lower wage).

The implication of this lemma is that the subset of agents of type $t$ who apply for job $i$ consists of the range of agents whose qualities fall between two bounds: an upper bound $\bar{q}_{i}^{t}$ and a lower bound $\bar{q}_{i+1}^{t}$. Agents with quality greater than $\bar{q}_{i}^{t}$ apply instead for jobs with higher wages while agents with quality less than $\bar{q}_{i+1}^{t}$ apply for jobs with lower wages.

Since employers hire any applicant whose expected quality exceeds $b_{i}$, the critical signal, $s_{t i}^{*}$, solves:

$$
B_{t}\left(s_{t i}^{*}, \bar{q}_{i+1}^{t}, \bar{q}_{i}^{t}\right)=b_{i}
$$

Substituting (1) into (3) provides,

$$
\left(\frac{1}{\int_{\bar{q}_{i+1}^{t}}^{\bar{q}_{i}^{t}} g^{t}\left(s_{t i}^{*}-u\right) d F^{t}(u)}\right) \int_{\bar{q}_{i+1}^{t}}^{\bar{q}_{i}^{t}} u g^{t}\left(s_{t i}^{*}-u\right) d F^{t}(u)=b_{i} .
$$

which when simplified gives the first condition that must be satisfied in equilibrium,

$$
\int_{\bar{q}_{i+1}^{t}}^{\bar{q}_{i}^{t}}\left(u-b_{i}\right) g^{t}\left(s_{t i}^{*}-u\right) d F^{t}(u)=0
$$

Employers have rational expectations about who will apply for their job. They correctly infer that any agent of type $t$ with quality between $\bar{q}_{i+1}^{t}$ and $\bar{q}_{i}^{t}$ optimally chooses to apply for the $i^{\text {th }}$ job and any agent of this type whose quality does not lie within these bound does not apply. Since $P_{t}(q, i)$ is continuous in $q$ and since there is a strictly positive probability that agents of both types exist who have such low quality they are unable to get anything but the reservation wage, this condition will be satisfied if and only if, for each type $t$ and job $i$,

$$
w_{i+1} P_{t}\left(\bar{q}_{i+1}^{t}, i+1\right)=w_{i} P_{t}\left(\bar{q}_{i+1}^{t}, i\right) .
$$


Using (2) provides the second condition that must be satisfied in equilibrium,

$$
w_{i+1}\left(1-G^{t}\left(s_{t i+1}^{*}-\bar{q}_{i+1}^{t}\right)\right)=w_{i}\left(1-G^{t}\left(s_{t i}^{*}-\bar{q}_{i+1}^{t}\right)\right)
$$

Finally, in equilibrium the job market must clear — all available jobs must be filled. This implies that

$$
\begin{aligned}
n_{i} & =N_{h} \int_{\bar{q}_{i+1}^{h}}^{\bar{q}_{i}^{h}} P_{h}(u, i) d F^{h}(u)+N_{l} \int_{\bar{q}_{i+1}^{l}}^{\bar{q}_{i}^{l}} P_{l}(u, i) d F^{l}(u) \\
& =N_{h} \int_{\bar{q}_{i+1}^{h}}^{\bar{q}_{i}^{h}}\left(1-G^{h}\left(s_{h i}^{*}-u\right)\right) d F^{h}(u)+N_{l} \int_{\bar{q}_{i+1}^{l}}^{\bar{q}_{i}^{l}}\left(1-G^{l}\left(s_{l i}^{*}-u\right)\right) d F^{l}(u) .
\end{aligned}
$$

Formally, then, an equilibrium in this economy is defined to be any set of wages, quality

bounds and critical signals $\left\{w_{i},\left\{\bar{q}_{i}^{t}, s_{t i}^{*}\right\}_{t=l, h}\right\}_{i=1}^{I}$ that simultaneously satisfy (5), (7) and (8).

The existence of the reservation wage guarantees that every employee who applies for a job must have a positive probability of getting the job. The following lemma states this fact (without proof).

Lemma 3.3 In equilibrium, for each type $t \in\{h, l\}$ and every $i=1 \ldots I, \bar{q}_{i+1}^{t}+\Delta_{t}>s_{t i}^{*}$.

\subsection{Other Restrictions}

It is possible for the equilibrium defined above to be economically uninteresting. For example, if in any sector $i$, the equilibrium features $w_{i}>b_{i}$, then in at least some cases, employers will be paying their employees above their expected marginal product. A rational employer would choose not to hire at all rather than hire employees under such conditions. This can occur in the model because we do not model the presumably endogenous process that determines the number of jobs available and number of sectors.

Competition between employers will drive $w_{i}$ up to $b_{i}$, so in a model with perfect competition $b_{i}$ cannot be strictly greater than $w_{i}$ either. In the spirit of Arrow's (1972) critique, we will impose the perfect competition assumption by restricting attention to equilibria for which $b_{i}=w_{i}$ for all $i$. However, since wages are easily observable but employment criteria are not, we will state all of our results in terms of wages. In fact this restriction does not affect any result in the paper, so this convention has the advantage that the results can then also be applied to non-competitive labor markets, i.e., equilibria for which $b_{i}>w_{i}$.

Another endogenous process that is not modeled is the optimal amount of investigation undertaken by each employer. That is, the signal noise is presumably also determined as a result of a tradeoff between the cost of investigation and the cost of making a mistake. From a practical perspective one would not expect investigation costs to be so high that 
an employer would not be able to recognize the best qualified applicant he could ever hope to attract. This being the case, we will further restrict attention to equilibria such that for each type $t$ and in every sector $i, G^{t}\left(s_{t i}^{*}-\bar{q}_{i}^{t}\right)=0$ - if the best possible candidate who could apply for a job applies, he cannot get a signal realization that would deny him the job. This assumption obviously implies that $\Delta_{t}<\bar{q}_{i}^{t}-s_{t i}^{*}$, for all $t$ and $i$. As we will show in Section 5, one;./ example of a distribution of $\delta^{t}$ that guarantees that this condition is satisfied is the Uniform distribution.

The condition that $G^{t}\left(s_{t i}^{*}-\bar{q}_{i}^{t}\right)=0$ can be used to simplify (5) and (7):

$$
\begin{aligned}
\int_{\bar{q}_{i+1}^{t}}^{s_{t i}^{*}+\Delta_{t}}\left(u-b_{i}\right) g^{t}\left(s_{t i}^{*}-u\right) d F^{t}(u) & =0 \\
w_{i}\left(1-G^{t}\left(s_{t i}^{*}-\bar{q}_{i+1}^{t}\right)\right) & =w_{i+1} .
\end{aligned}
$$

Thus, (9) and (10) can replace (5) and (7) in the definition of the job market equilibrium.

\section{The Nature of the Discrimination}

Employees of the same quality (marginal product) perform every job in the economy equally well regardless of their type. Consequently, we interpret employee type as one of the characteristics singled out under anti-discrimination law (e.g., race or sex). Legal discrimination therefore occurs in this model whenever an employer uses an employee's type in the hiring decision, that is, whenever $s_{h i}^{*} \neq s_{l i}^{*}$. If $s_{l i}^{*}>s_{h i}^{*}$, agents of type $l$ have to pass a higher hurdle in order to get the $i^{\text {th }}$ job and so are defined to be legally discriminated against. We will say that the economy features systematic legal discrimination against agents of type $l$ when $s_{l i}^{*} \leq s_{h i}^{*}$ for every $i=1, \ldots, I$ - in every sector of the economy no agent of type $l$ is favored over an agent of type $h$.

In an economy with legal discrimination the possibility exists that the average wage of applicants of identical quality might depend on applicant type and so the equilibrium will feature economic discrimination. In such an equilibrium, if for a given quality level $q$, the average wage of type $h$ agents exceeds that of type $l$ agents, then type $l$ agents of quality $q$ are defined to be economically discriminated against. The economy features systematic economic discrimination against agents of type $l$ when for every quality level $q \in Q^{h} \cap Q^{l}$, the average wage of all agents of type $h$ and quality $q$ is no less than the average wage of all agents of type $l$ and quality $q$.

We first consider the case when there is no difference between the signal noise in the two groups. In this case, any discrimination that results derives exclusively from quality differences. We then consider the case when the distribution of quality is the same for both groups, but one group has a less informative signal. Finally, we consider the case when 
both the signal noise and the distribution of quality differs between the two groups.

\subsection{Different Underlying Quality Distributions}

Throughout this subsection we consider the case when the signal noise does not depend on the agent's type, that is, we assume that $G_{h}=G_{l}=G$, so $\Delta_{h}=\Delta_{l}=\Delta$. Define

$$
Q^{i} \equiv\left[b_{i+1}, b_{i-1}\right] \cap Q^{h} \cap Q^{l}
$$

Note that this set must contain the set $\left[\bar{q}_{i+1}^{h}, \bar{q}_{i}^{h}\right] \cap\left[\bar{q}_{i+1}^{l}, \bar{q}_{i}^{l}\right]$, the set of possible applicants to the $i^{\text {th }}$ job that have the same quality but could be of either type. The following proposition shows that a sufficient condition for legal discrimination is that monotone likelihood property holds over the set $Q^{i}$.

Proposition 1 If $\frac{f^{h}}{f^{l}}$ is strictly increasing on $Q^{i}$, in equilibrium the $i^{\text {th }}$ employer will legally discriminate against employees of type l, i.e., $s_{l i}^{*}>s_{h i}^{*}$, and as a result $\bar{q}_{i+1}^{l}>\bar{q}_{i+1}^{h}$.

Note that the monotone likelihood ratio property implies stochastic dominance, but the reverse is not true. As we demonstrate explicitly in Section 5 it is possible for some employers to discriminate against agents of type $h$ even if $F^{h}$ stochastically dominates $F^{l}$. As the proposition makes clear, a strong condition is required to get systematic legal discrimination.

When the condition in Proposition 1 is satisfied, the next proposition shows that economic discrimination results. Before we state and prove this result, note that since employees have rational expectations, the expected wage of a type $t$ employee of quality $q$ will also be the average wage of all type $t$ employees of quality $q$. Thus, to show that economic discrimination exists, it is sufficient to show that the expected wage of employees of the same quality but of different types, differs.

Proposition 2 In any equilibrium in which $s_{h i}^{*}<s_{l i}^{*}$, every agent of type $l$ and quality between $\bar{q}_{i+1}^{h}$ and $s_{l i}^{*}+\Delta$ will be economically discriminated against.

The proposition shows that whenever legal discrimination exists economic discrimination must also exist. One might conjecture that this result will be true even when the signal noise differs across agent types. We show, in the next subsection, that this is not the case.

The next proposition derives a sufficient condition for systematic legal and economic discrimination.

Proposition 3 If $\frac{f^{h}}{f^{l}}$ is strictly increasing on $Q^{h} \cap Q^{l}$ then the equilibrium will feature systematic legal and economic discrimination against agents of type $l$. 


\subsection{Different Distributions of the Signal Noise}

In this subsection we consider the case when the underlying distribution of quality is identical in the two groups, but employers are able to measure quality better in one group than the other: $F^{h}=F^{l}=F$ and $G^{h} \neq G^{l}$. The following definition is needed to provide an ordering over noise distributions:

Definition: Type $h$ agents are said to be less familiar than type $l$ agents if for all $x$ such that $0<x<\Delta_{l}\left(-\Delta_{l}<x<0\right), \frac{g^{h}}{g^{l}}$ is strictly increasing (decreasing).

This definition together with the symmetry of $g^{t}$ implies that if $h$ agents are less familiar than type $l$ agents, then for $\delta \in\left(-\Delta_{h}, 0\right), G^{h}(\delta)>G^{l}(\delta)$ and for $\delta \in\left(0, \Delta_{h}\right), G^{l}(\delta)>G^{h}(\delta)$ - there is more probability mass in the tails of $g^{h}$ than $g^{l}$. Thus a signal from a type $h$ agent is less informative in the sense that for any fixed deviation, $D$, the probability that it will deviate from true quality by more than $D$ is strictly greater for type $l$ agents than it is for type $h$ agents. This is the sense that type $l$ agents are "less familiar."

The next proposition shows that so long as the wage of any job is no larger than twice the wage of the next best job, legal discrimination always results and favors the less familiar group:

Proposition 4 Let type $h$ agents be less familiar than type l agents. If $\frac{w_{i}}{w_{i+1}} \leq 2$ then the $i^{\text {th }}$ employer will legally discriminate in favor of employees of the less familiar type. That $i s, s_{l i}^{*}>s_{h i}^{*}$.

So long as the wage of any job does not exceed twice the wage of the next worst job, if both groups have the same underlying distribution, systematic legal discrimination against the group with the lower signal noise will exist. Recall that $w_{i}=b_{i}$, so for equilibria with no economic rents, this condition reduces to the relatively weak requirement that hiring standards in any sector cannot be twice has high as the next worst sector.

Relative to the sufficient condition derived in Proposition 1, the condition in Proposition 4 is remarkably weak. On the surface anyway, this result seems counter-intuitive. However, it derives directly from the fact that employees select the job they apply for: when wage differences are not too large, the average quality of candidates applying for the $i^{\text {th }}$ job exceeds $b_{i}$. To see why this provides the result, consider an extreme case in which $F^{h}=F^{l}$ and $\Delta_{l}=0$ but $\Delta_{h}>0$. For candidates of type $l$ the signal completely reveals the true quality so $s_{l i}^{*}=b_{i}$. Now consider a candidate of type $h$ who arrives with a signal $b_{i}$. Because the average quality of candidates applying for the job exceeds $b_{i}$, when the employer uses his prior knowledge of the distribution of candidates who apply, he will infer that the expected 
quality of an agent with signal $b_{i}$ exceeds $b_{i}$. Thus the critical signal for candidates of type $h$ must be less than $b_{i}$.

Since the critical signal is always higher for the group with the smaller signal noise, this group suffers from systematic legal discrimination. Systematic economic discrimination nevertheless does not necessarily exist in this economy. If we continue the thought experiment in the previous paragraph, it is easy to see why. Type $h$ employees of quality just below $b_{i}$ choose to apply for the $i^{t h}$ job so their expected wages must exceed $w_{i+1}$, the wage of type $l$ employees of the same quality. The reverse is true for employees of quality just above $b_{i}$. Type $h$ employees cannot get the job for sure (otherwise (10) could not be satisfied) so their expected wages are strictly less than $w_{i}$, the expected wage of type $l$ employees.

The reason that legal discrimination does not necessarily lead to economic discrimination is that economic discrimination is defined in terms of differences in average wages without any regard to where these differences originate. Note the even if there were no legal discrimination in the thought experiment ( so that $s_{h i}^{*}=b_{i}$ ), economic discrimination would still exist.

In light of how weak the conditions are that guarantee legal discrimination in the economy, the following proposition follows immediately:

Proposition 5 Let type $h$ agents be less familiar than type $l$ agents. If for every $i=$ $1, \ldots, I, \frac{w_{i}}{w_{i+1}} \leq 2$ then the equilibrium will feature systematic legal discrimination against agents of type $l$.

So long as employers act optimally in this model, Proposition 5 implies that the possibility that measurement discrimination, by acting to reduce the incentive of one group to adopt self-improving technologies, might in turn lead to qualification discrimination (as in Lundberg and Startz (1983)) is unlikely. Although legal discrimination is likely to exist, the differences in expected wages are unlikely to systematically disadvantage any one group. Given the large uncertainty in both how much an investment in education will increase an individual's marginal product as well as in future wages, it would be extremely difficult for an individual member of either type to tell, ex ante, whether an investment in education would be more productive ex post, were she of another type. ${ }^{9}$

\subsection{Differences both in the Underlying Quality and the Signal Noise}

In this subsection we consider economies for which $F^{h} \neq F^{l}$ and $G^{h} \neq G^{l}$. The results follow directly from the results of the previous two subsections:

\footnotetext{
${ }^{9}$ This is also consistent with the recent empirical evidence (see, for example, Kuhn (1987) or Neal and Johnson (1996))
} 
Proposition 6 Let type $h$ agents be less familiar than type $l$ agents. If $\frac{w_{i}}{w_{i+1}} \leq 2$ and $\frac{f^{h}}{f^{l}}$ is strictly increasing on $\left[b_{i+1}, b_{i-1}\right]$, in equilibrium the $i^{\text {th }}$ employer will legally discriminate against employees of type l, i.e., $s_{l i}^{*}>s_{h i}^{*}$.

The next proposition follows immediately from this proposition and is stated without proof:

Proposition 7 Let type $h$ agents be less familiar than type $l$ agents. If for every $i=$ $1, \ldots, I, \frac{w_{i}}{w_{i+1}} \leq 2$ and $\frac{f^{h}}{f^{l}}$ is strictly increasing on $Q^{\cup}$, in equilibrium the systematic legal discrimination against employees of type $l$ will exist.

Note that comparable results cannot be derived for economic discrimination. In this case the discrimination depends on the relative magnitude of the differences in the signal noise and underlying quality. Also, when the conditions in Proposition 7 do not hold, the relative magnitudes of the two factors that cause the discrimination will be important in determining who suffers from the discrimination. Since the relative importance of the factors depends on characteristics of the specific distributions, to draw inferences it is necessary to further restrict these distributions. In the Section 5 we will attempt to gain some insight into the relative importance of the factors by considering three specific cases.

\section{Interaction Between Quality Differences and Noise Differ- ences}

In this section of the paper we will consider three specific cases. In all three cases we assume that $\delta$ is distributed Uniform $\left[-\Delta_{t}, \Delta_{t}\right]$. In the first case we will assume that quality is also uniformly distributed. In this case we are able to obtain closed form solutions. In the two remaining cases we assume that quality is distributed under a Normal and a Cauchy distribution. In these cases, closed form expressions are not attainable, and so we rely on numerical methods.

In all three cases examined we find that the resulting qualification discrimination is small relative to the assumed quality differences across types. This is not true for measurement discrimination. In all three cases, differences in the signal noise leads to significant legal and economic discrimination. However the type that benefits depends on quality. Interestingly, commonly used measures of discrimination such as average wages and the ratio of each type employed in each sector convey the opposite results. That is, qualification discrimination leads to large average wage differences as well as ratios within the sector quite different to the ratio of each type in the economy as a whole. Measurement discrimination, on the other hand, leads to almost no average wage differences and ratios in the sectors that mirror the ratio of each type in the economy as a whole. 
Lemma B.2, in the appendix, shows that if $\delta$ is distributed Uniform $\left[-\Delta_{t}, \Delta_{t}\right]$ in every equilibrium $G^{t}\left(\bar{q}_{i}^{t}-s_{t i}^{*}\right)=0 \forall i$ - if the best possible applicant applies for the job, he will get it for sure. This assumption can be used to simplify the equilibrium conditions further. From (7) we get,

$$
w_{i+1}=w_{i} \frac{\left(\Delta_{t}-s_{t i}^{*}+\bar{q}_{i+1}^{t}\right)}{2 \Delta_{t}}, \quad i=1, \ldots, I .
$$

Solving for $\bar{q}_{i+1}^{t}$ provides:

$$
\begin{aligned}
\bar{q}_{i+1}^{t} & =2 \Delta_{t} \frac{w_{i+1}}{w_{i}}+s_{t i}^{*}-\Delta_{t} \\
& =s_{t i}^{*}+W_{i} \Delta_{t}, \quad i=1, \ldots, I
\end{aligned}
$$

where $W_{i} \equiv 2 \frac{w_{i+1}}{w_{i}}-1<1$. Using this relation and the Uniform assumption, (9) becomes

$$
\int_{s_{t i}^{*}+W_{i} \Delta_{t}}^{s_{t i}^{*}+\Delta_{t}}\left(u-b_{i}\right) d F^{t}(u)=0 .
$$

Thus, (12) and (13) can replace (10) and (9) in the definition of the job market equilibrium.

Under the Uniform assumption, systematic legal discrimination that results from differences in signal noise can never, by itself, lead to systematic economic discrimination. The following proposition proves this.

Proposition 8 Assume that $F^{h}=F^{l}$ and the condition in Proposition 5 holds. Then systematic economic discrimination will not exist.

\subsection{Case I: Uniformly Distributed Agents}

Assume that the underlying distribution of agent's quality for both types is uniform, that is,

$$
F^{l} \equiv U[0, \bar{l}] \text { and } F^{h} \equiv U[0, \bar{h}]
$$

where $\bar{h}>\bar{l}$. Substituting these underlying distributions into (12) provides,

$$
\int_{s_{t i}^{*}+W_{i} \Delta_{t}}^{s_{t i}^{*}+\Delta_{t}}\left(u-b_{i}\right) d u=0 .
$$

Integrating (15) gives,

$$
\frac{2 s_{t i}^{*}+\Delta_{t}\left(1+W_{i}\right)}{2}-b_{i}=0
$$

Solving for $s_{t i}^{*}$ yields,

$$
s_{t i}^{*}=b_{i}-\frac{\Delta_{t}}{2}\left(1+W_{i}\right) .
$$


By assumption, this equation only holds for jobs to which employees apply. If in every sector $i, n_{i}>0$, for type $h$ applicants, (16) holds for all jobs. To determine which jobs type $l$ applicants apply for, note that

$$
s_{l i}^{*} \leq \bar{l}-\Delta_{l},
$$

for any $i$ to which type $l$ applicants apply. Using (16) provides,

$$
b_{i} \leq \bar{l}-\frac{\Delta_{l}}{2}\left(1-W_{i}\right)
$$

Thus, the set of jobs that type $l$ employees apply to is restricted to the set $A \equiv\left\{i \mid b_{i} \leq\right.$ $\left.\bar{l}-\frac{\Delta_{t}}{2}\left(1-W_{i}\right)\right\}$. Define $\iota$ as the smallest element of $A$.

When $\Delta_{h}=\Delta_{l}=\Delta$, that is, the employer's estimate of an applicants true quality is independent of the applicant's type, then, from (16), for the jobs that both types apply to, $s_{t i}^{*}$ does not depend on $t$. For these jobs the critical signal is the same for both types and so there is no legal discrimination. This result does not depend on the relative values of $\bar{h}$ and $\bar{l}$. There is no discrimination in the economy even though $F^{h}$ stochastically dominates $F^{l}$.

By substituting (16) into (13) and solving for $\bar{q}_{i}^{t}$ in terms of the primitives we get,

$$
\bar{q}_{i+1}^{t}=b_{i}-\frac{\Delta}{2}\left(1-W_{i+1}\right)
$$

where $i$ is restricted to the set $A$ for $t=l$. Since the right hand side of this equation is not a function of type, $\bar{q}_{i+1}^{t}$ is not a function of type. However, (17) does not provide the upper bound on the best job agents apply to (this bound is given by the upper bound of the quality distribution). Therefore for any job except perhaps for job $\iota$, all agents of the same quality choose to apply for the same jobs.

For job $\iota$ (the best job type $l$ agents apply for), if $\bar{q}_{l}^{h} \geq \bar{l}$ then the value of $\bar{l}$ does not affect the analysis and so the above inference, that agents of the same quality apply for the same jobs holds for job $\iota$ as well. Since any applicant's probability of getting a job is independent of type (by (16)), for a given quality level, the average wage will not differ between types and so no economic discrimination exists in the economy. If, on the other hand, $\bar{q}_{l}^{h}<\bar{l}$ then some high quality type $l$ agents might exist who choose not to apply for the same job that type $h$ agents of the same quality apply for. To see why, note that agents of type $l$ with quality between $\bar{q}_{l}^{h}$ and $\bar{l}$ apply for job $\iota$ while agents of type $h$ with quality between $\bar{q}_{\iota}^{h}$ and $\bar{l}$ apply for job $\iota-1 .{ }^{10}$ Thus this subset of agents alone will have different average wages and so the type $l$ agents in this subset will suffer economic discrimination.

\footnotetext{
${ }^{10}$ Recall, from Lemma B.2, that every job that agents apply for must include the possibility that an agent of sufficiently high quality will apply who will get the job for sure. Thus agents of type $l$ with quality between $\bar{q}_{\iota}^{h}$ and $\bar{l}$ cannot apply for job $\iota-1$ because no type $l$ agent exists who could get that job for certain.
} 
For all other sectors $i$ such that $i>\iota$, however, there is no economic or legal discrimination.

Different results obtain when $\Delta_{h} \neq \Delta_{l}$ so that the signal noise differs between groups. By (16), $s_{t i}^{*}$ is a decreasing function of $\Delta_{t}$ so the less familiar group is legally discriminated against. In this case the effect of the measurement uncertainty dominates the uncertainty in quality. Increasing the relative values of $\bar{h}$ and $\bar{l}$ makes no difference to the resulting legal discrimination because it does not exist. Increasing the relative values of $\Delta_{h}$ or $\Delta_{l}$ has an effect on the resulting legal discrimination because by (16), $s_{t i}^{*}$ is a linear function of $\Delta_{t}$.

This example demonstrates an important difference between statistical discrimination that results from quality differences rather than differences in measurement error. When the only difference between employee types is the distribution of quality, employee self selection eliminates the discrimination in the example. On the other hand when differences result from employer familiarity the discrimination persists. To see why differentiate (16) to get:

$$
\frac{\partial s_{t i}^{*}}{\partial \Delta_{t}}=-\frac{w_{i+1}}{w_{i}}
$$

Since $\frac{w_{i+1}}{w_{i}}<1$, the difference in the critical signal between the two groups is always less than the signal differences, so employee self selection mitigates the discrimination. However,

because of the existence of the reservation wage, $\frac{w_{i+1}}{w_{i}}>0$, so the discrimination cannot be removed entirely.

In the case of quality differences the self selection directly affects the underlying reason for discriminating in the first place by altering the conditional quality distributional differences between types. In the case of measurement differences, the self-selection bias does not affect the signal noise and so does not directly affect the underlying cause of the discrimination. It therefore cannot completely eliminate the effect of differences in signal noise.

\subsection{Case II: Normally Distributed Agents}

In this section we will consider a job market were agent's qualities are distributed normally, that is, we assume that

$$
F^{l} \equiv \operatorname{Normal}[9,2.5] \text { and } F^{h} \equiv \operatorname{Normal}[11,2]
$$

The total number of employees is normalized to 1 , and it is assumed that there is an equal fraction of type $h$ and type $l$ employees. There are 10 different job sectors with $b_{i}=22-2 i$, $i=1, \ldots, 10$. Recall that employers do not make economic rents off their employees so $w_{i}=b_{i}$. This marginal product (wage) schedule is selected so that the ratio of the highest marginal product (wage) to the reservation wage is 20 . To ensure existence, we set the number of jobs in each sector equal to the supply of available employees. 
These two distributions, as well as the minimum required quality and wage for each job are plotted in Figure 1, Panel A. Agents of type $h$ are therefore "better" both in terms of average quality and in terms of the fact that quality is less dispersed $-F^{h}$ second order stochastically dominates $F^{l}$. Nevertheless, as Figure 1, Panel B demonstrates the likelihood ratio is not monotone over all job sectors. As a result, the direction of the discrimination in equilibrium will not always favor one type.

\section{Figure 1: Quality Distributions}

The curves are two normal distributions and the light curves are the two Cauchy distributions. Panel A plots the respective density functions, and panel B plots the likelihood ratio, $\frac{f^{h}}{f^{l}}$. The vertical gray lines on the even numbers mark the wage offered by employers as well as employers' minimal acceptable expected quality (marginal product). The vertical gray line at one is the reservation wage in the economy.

A: Density Functions

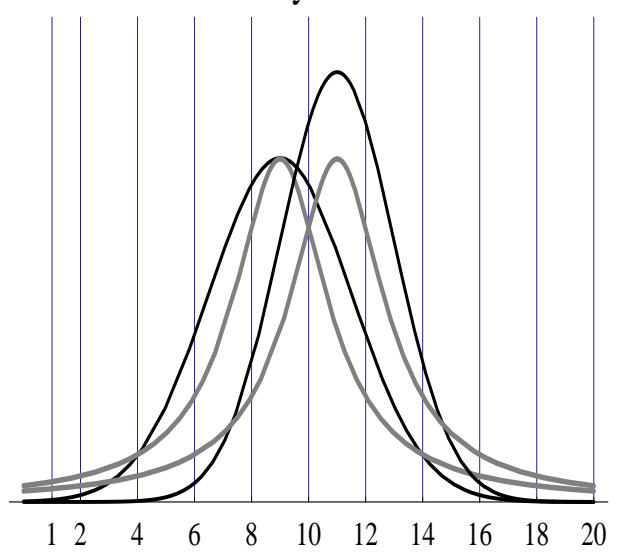

B: Likelihood Ratio

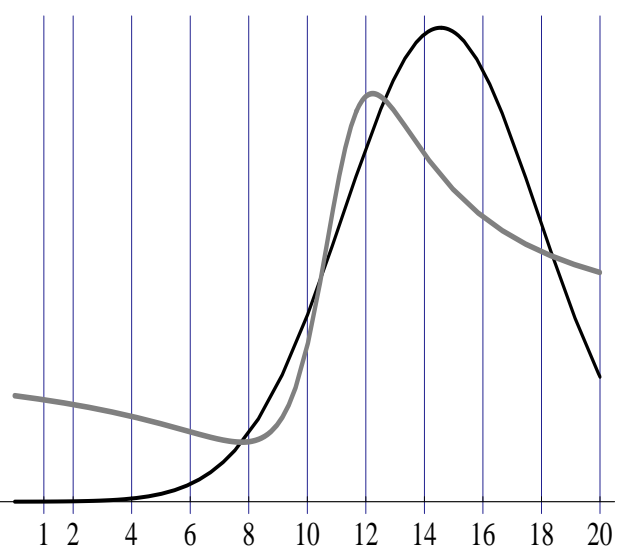

Substituting the distributional assumption into (13) and integrating gives:

$e^{-\frac{\left(s_{l i}^{*}+\Delta_{t}-9\right)^{2}}{12.5}}-e^{-\frac{\left(s_{l i}^{*}+\Delta_{t} W_{i}-9\right)^{2}}{12.5}}+\left(b_{i}-9\right) \sqrt{\frac{8 \pi}{25}}\left(N\left(\frac{s_{l i}^{*}+\Delta_{t}-9}{2.5}\right)-N\left(\frac{s_{l i}^{*}+\Delta_{t} W_{i}-9}{2.5}\right)\right)=0$

and

$e^{-\frac{\left(s_{h i}^{*}+\Delta_{t}-11\right)^{2}}{8}}-e^{-\frac{\left(s_{h i}^{*}+\Delta_{t} W_{i}-11\right)^{2}}{8}}+\left(b_{i}-11\right) \sqrt{\frac{\pi}{2}}\left(N\left(\frac{s_{h i}^{*}+\Delta_{t}-11}{2}\right)-N\left(\frac{s_{h i}^{*}+\Delta_{t} W_{i}-11}{2}\right)\right)=0$,

where $N(x)$ is the standard normal distribution function. The solution to these equations provides the equilibrium $s_{t i}^{*}$, for each type $t$. Equation (12) can then be used to derive the equilibrium $\bar{q}_{i}^{t} \cdot n_{i}$ is then set by (8). 
We first consider the case when the signal noise does not depend on the agent's type, i.e., $\Delta_{h}=\Delta_{l}=\Delta=1.95 . \Delta$ is chosen to be close to the maximum that still ensures that every sector has a positive number of employees. The equilibrium is reported in Table 1.

It is quite striking how small the difference in critical signals is between the two groups of agents. Even though average quality differs by 2 (one standard deviation of $f^{h}$ ), in no case does the critical signal difference exceed 0.1. As predicted by Figure 1, Panel B, the direction of the discrimination favors type $l$ agents in the better sectors where the likelihood ratio is decreasing. In this example, the group with the better average quality is discriminated against in the first four job sectors and benefits from the discrimination in the other sectors. This is true both for legal discrimination (see Table 1, rows 3 and 4) and economic discrimination (see Figure 3, dark curve).

\section{Table 1: The Equilibrium in the Economy with Normal Agents with Identical Signal Noise}

Quality (marginal product) is distributed Normal[9, 2.5] for agents of type $l$, Normal[11,2] for agents of type $h$ and $\Delta_{h}=\Delta_{l}=1.95$. The fraction of employees employed $(n)$, the offered wage or minimal expected marginal product $(w)$, the equilibrium critical signal $\left(s_{h}^{*}\right.$ and $\left.s_{l}^{*}\right)$, the upper bound on quality $\left(\bar{q}^{h}\right.$ and $\left.\bar{q}^{h}\right)$ and the fraction of each type employed in each sector $\left(n_{h}\right.$ and $\left.n_{l}\right)$ are listed below. The final two rows $\left(E_{h}[w \mid i]\right.$ and $\left.E_{l}[w \mid i]\right)$ are the expected wage of all employees of a particular type who choose to apply in the $i^{\text {th }}$ sector. The overall fraction of employees employed $(n)$ and the fraction by type $\left(n_{h}\right.$ and $\left.n_{l}\right)$ are listed in percent. The final column contains these values for the reservation job in the economy.

\begin{tabular}{|c||c|c|c|c|c|c|c|c|c|c|c||}
\hline \hline \multicolumn{1}{|c||}{} & \multicolumn{1}{c|}{ Job } & \multicolumn{1}{c||}{ res } \\
\hline \hline$n$ & 0.0006 & 0.026 & 0.541 & 4.94 & 18.93 & 31.45 & 25.14 & 11.31 & 2.85 & 0.257 & 0.022 \\
\hline$w$ & 20.0 & 18.0 & 16.0 & 14.0 & 12.0 & 10.0 & 8.0 & 6.0 & 4.0 & 2.0 & 1.0 \\
\hline$s_{h}^{*}$ & 18.273 & 16.294 & 14.318 & 12.348 & 10.384 & 8.427 & 6.478 & 4.53 & 2.54 & 0.46 & $-\infty$ \\
\hline$s_{l}^{*}$ & 18.267 & 16.289 & 14.316 & 12.349 & 10.392 & 8.448 & 6.525 & 4.63 & 2.76 & 0.69 & $-\infty$ \\
\hline $\bar{q}^{h}$ & $\infty$ & 19.833 & 17.811 & 15.781 & 13.741 & 11.684 & 9.597 & 7.45 & 5.18 & 2.54 & 0.46 \\
\hline $\bar{q}^{l}$ & $\infty$ & 19.827 & 17.806 & 15.778 & 13.742 & 11.692 & 9.618 & 7.50 & 5.28 & 2.77 & 0.69 \\
\hline$n_{h}$ & 0.0005 & 0.031 & 0.779 & 7.41 & 27.12 & 37.91 & 19.68 & 3.50 & 0.172 & 0.0011 & 0.000 \\
\hline$n_{l}$ & 0.0007 & 0.020 & 0.303 & 2.47 & 10.75 & 25.00 & 30.61 & 19.11 & 5.52 & 0.512 & 0.044 \\
\hline$E_{h}[w \mid i]$ & 19.31 & 17.36 & 15.43 & 13.50 & 11.58 & 9.66 & 7.74 & 5.80 & 3.84 & 1.84 & 1.0 \\
\hline$E_{l}[w \mid i]$ & 19.43 & 17.44 & 15.47 & 13.50 & 11.53 & 9.55 & 7.57 & 5.57 & 3.55 & 1.72 & 1.0 \\
\hline \hline
\end{tabular}

The difference between the expected wages of identical agents from different groups is so small that it is almost indistinguishable on the plot of expected wages (Figure 2, dark curves). This difference, as a fraction of the expected wage of the agent of type $l$, is plotted in Figure 3. ${ }^{11}$ In all cases the difference in the expected wage of the two types is within

\footnotetext{
${ }^{11}$ The peculiar shape of the plot is easily explained. Regions in which the difference is zero correspond
} 
Figure 2: Expected Wages in the Economy with Normal Agents

The expected wage of an agent of quality $q$, is the probability of getting the job this agent chooses to apply for multiplied by the wage offered for this job. The dark (dashed) curve is the expected wage of type $h(l)$ agents in the economy with different quality distributions but the same signal noise, i.e., $\Delta_{h}=\Delta_{l}=1.95$. The light curve is the expected wage of an agent with the type $h$ quality distribution, but with signal noise $\Delta=1.0$. The vertical gray lines mark the offered wage or minimal expected marginal product for each respective job.

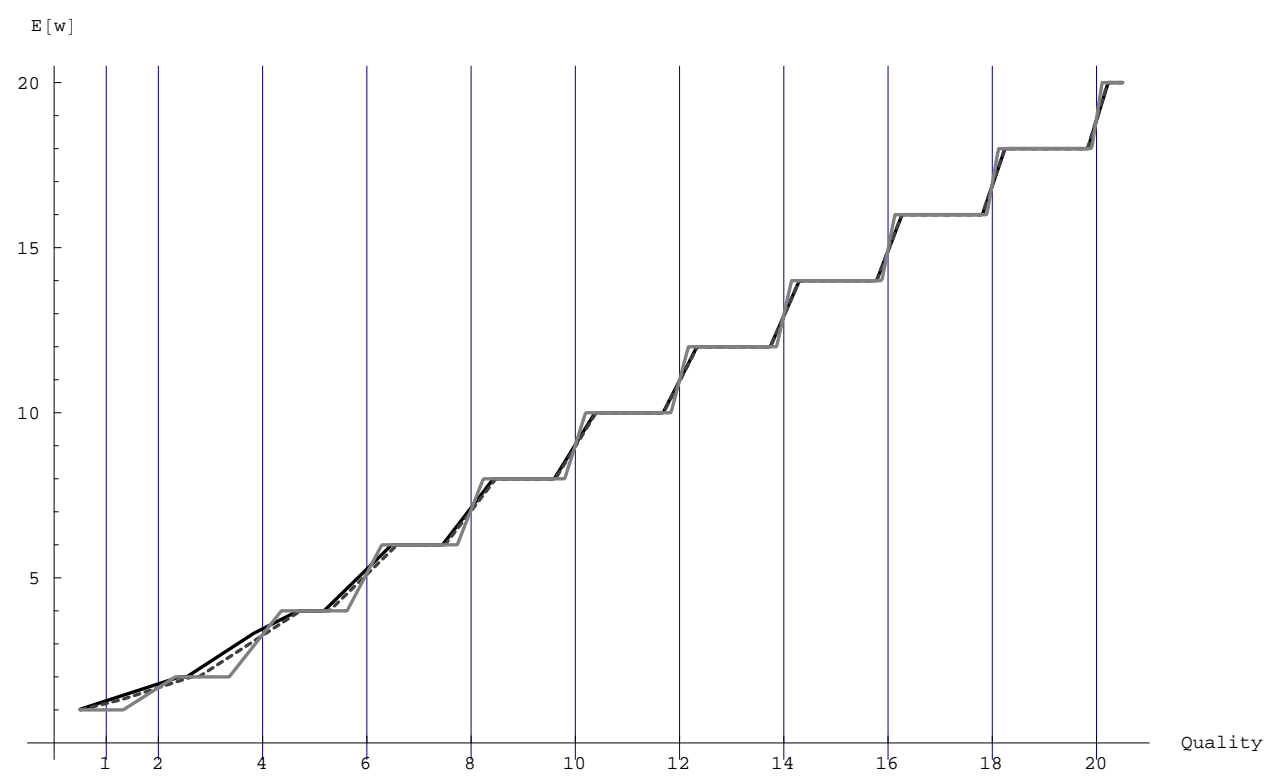


$12 \%$ of the expected wage of the $l$ type.

One of the features of this equilibrium is that the absolute magnitude of the discrimination decreases as the quality of the job increases. The reason for this is that, given two jobs, the employee's decision about which job to apply for depends on the ratio of the wages of the two jobs (see (10)). Since this wage ratio decreases with job quality, relatively more applicants to the low paying jobs opt to take the risk and apply for a job they might not get rather than applying for the next worse job which they can get with certainty. Thus the regions in which the expected wages are the same (because both types choose to apply to jobs they can get for sure) increase as the jobs get better. Since the signals in these regions are fully revealing, the fraction of applicants with fully revealing signals is higher in the better jobs. Consequently, the average informativeness of the signal is higher, so the amount of discrimination is correspondingly lower.

Of course, from an empirical standpoint, since true quality is unobservable, the expected (or average) wage for a given quality level is unobservable. The final two rows of table address this issue by calculating the average wage of all applicants to a particular sector. Here again the differences are very small and the direction mirrors the direction of the economic discrimination in the economy. However, the average wage all type $h$ agents is 10.00 while it is only 8.01 for type $l$ agents. From a policy perspective this difference is important because it emphasizes that even though the amount of economic discrimination in this economy is small, because there are large average differences in quality across types, average wage differences are still very large.

When differences in types are driven by differences in signal noise, the magnitude of the resulting discrimination increases appreciably. Table 2 shows the equilibrium when quality is distributed identically Normal[11,2] for both types but $\Delta_{h}=1.95$ and $\Delta_{l}=1.0$. The difference in the critical signals is now larger than before reaching a maximum of 0.865 . Consequently, the average quality of applicants applying for any job is significantly lower in the $h$ group than the $l$ group. The magnitude of the economic discrimination is appreciably larger and, consistent with Proposition 5, it does not systematically favor any one type over the other (Figure 2). The percentage differences in expected wages (Figure 4) is surprisingly large (when compared to the previous case), reaching a maximum of about $45 \% .{ }^{12}$

to quality levels in which agents of both types are certain to get the job if they apply. Thus their expected wage is the same. Once one of the types (say $h$ ) chooses to apply to the next best job the curve rises rapidly, since as quality increases the probability of getting the job rises accordingly. Until quality increases to the point that agents of the other type $(l)$ choose to apply for the same job, the expected wage of the other type remains constant, hence the percentage difference increases dramatically. This rapid increase in the percentage difference is arrested at the point that both types choose to apply to same job. It then begins to slowly decrease because the curve is percent of the type $l$ expected wage. It begins to decrease rapidly once quality is increased to the point that the $h$ type is certain of getting the job and returns to zero once both types are certain of getting the job.

${ }^{12}$ This maximum occurs in the lowest paid job where the ratio of the wage to the wage of the next best job is large and so there are few quality levels in which employees reveal their marginal product by choosing 
Figure 3: Percentage Difference in Expected Wages in the Economy with Different Quality Distributions but Identical Signal Noise

The expected wage of an agent of quality $q$, is the probability of getting the job this agent chooses to apply for multiplied by the wage offered for this job. The percentage difference between the expected wage of two agents of the same quality is then defined to be the expected wage of the agent of type $h$ minus the expected wage of the agent of type $l$ divided by the expected wage of the agent of type $l$ (i.e., $\frac{E_{h}[w \mid q]-E_{l}[w \mid q]}{E_{l}[w \mid q]}$ ) expressed in percentage terms. The dark curve is economy with normally distributed agents and the light curve is the economy with Cauchy distributed agents.

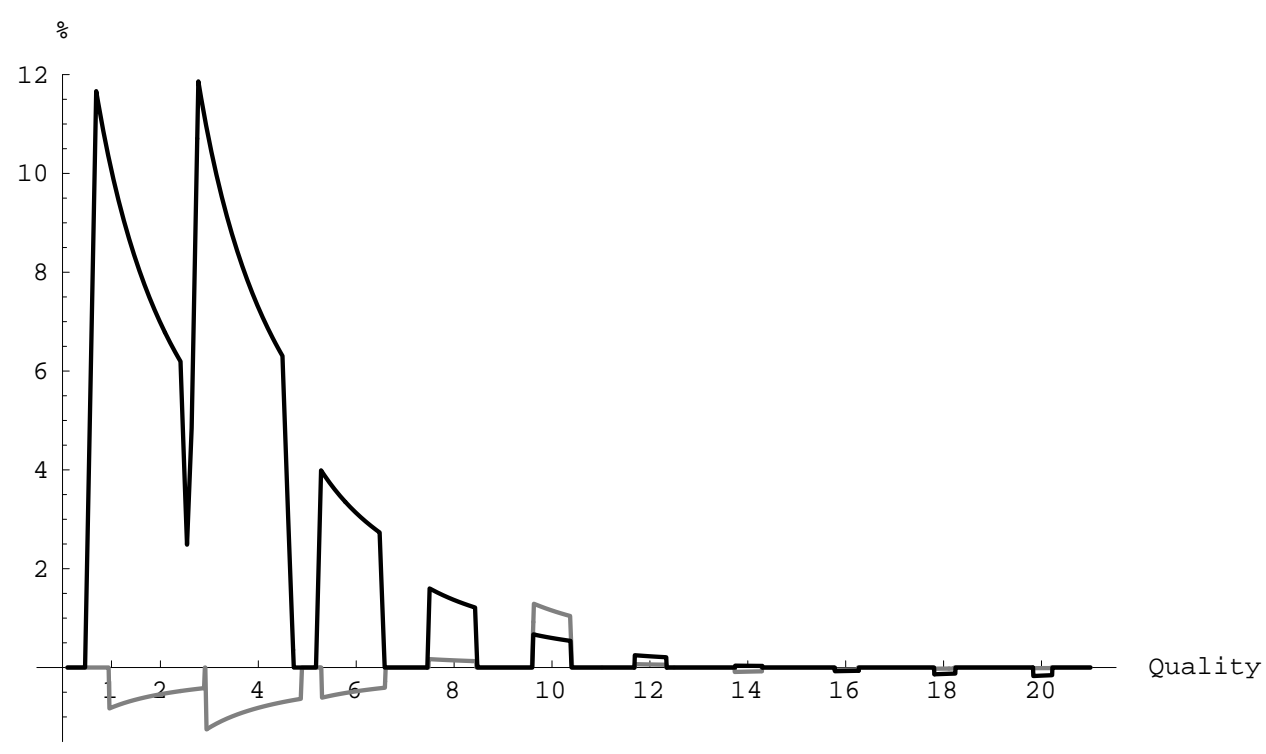


Table 2: The Equilibrium in the Economy with Identical Normal Agents with Differing Signal Noise

Quality (marginal product) is distributed Normal[11,2] for agents of both types. Agent's of type $l$ have smaller signal noise, i.e., $\Delta_{l}=1$ and $\Delta_{h}=1.95$. The fraction of employees employed $(n)$, the offered wage or minimal expected marginal product $(w)$, the equilibrium critical signal $\left(s_{h}^{*}\right.$ and $\left.s_{l}^{*}\right)$, the upper bound on quality $\left(\bar{q}^{h}\right.$ and $\left.\bar{q}^{h}\right)$ and the fraction of each type employed in each sector $\left(n_{h}\right.$ and $\left.n_{l}\right)$ are listed below. The final two rows $\left(E_{h}[w \mid i]\right.$ and $\left.E_{l}[w \mid i]\right)$ are the expected wage of all employees of a particular type who choose to apply in the $i^{\text {th }}$ sector. The overall fraction of employees employed $(n)$ and the fraction by type $\left(n_{h}\right.$ and $\left.n_{l}\right)$ are listed in percent. The final column contains these values for the reservation job in the economy.

\begin{tabular}{|c||c|c|c|c|c|c|c|c|c|c|c||}
\hline \hline \multicolumn{1}{|c||}{} & \multicolumn{1}{c|}{ Job } & \multicolumn{1}{c||}{ res } \\
\hline \hline$n$ & 0.00045 & 0.029 & 0.73 & 7.08 & 26.40 & 38.02 & 20.77 & 4.10 & 0.258 & 0.0038 & 0.00004 \\
\hline$w$ & 20.0 & 18.0 & 16.0 & 14.0 & 12.0 & 10.0 & 8.0 & 6.0 & 4.0 & 2.0 & 1.0 \\
\hline$s_{h}^{*}$ & 18.27 & 16.29 & 14.32 & 12.35 & 10.38 & 8.427 & 6.478 & 4.528 & 2.543 & 0.4604 & $-\infty$ \\
\hline$s_{l}^{*}$ & 19.11 & 17.12 & 15.13 & 13.15 & 11.17 & 9.197 & 7.234 & 5.287 & 3.360 & 1.325 & $-\infty$ \\
\hline $\bar{q}^{h}$ & $\infty$ & 19.83 & 17.81 & 15.78 & 13.74 & 11.68 & 9.597 & 7.453 & 5.178 & 2.543 & 0.4604 \\
\hline $\bar{q}^{l}$ & $\infty$ & 19.91 & 17.90 & 15.88 & 13.86 & 11.84 & 9.797 & 7.734 & 5.621 & 3.360 & 1.325 \\
\hline$n_{h}$ & 0.0005 & 0.032 & 0.78 & 7.41 & 27.12 & 37.91 & 19.68 & 3.50 & 0.172 & 0.0011 & 0.00001 \\
\hline$n_{l}$ & 0.0004 & 0.027 & 0.69 & 6.75 & 25.69 & 38.14 & 21.87 & 4.69 & 0.344 & 0.0065 & 0.00007 \\
\hline$E_{h}[w \mid i]$ & 19.31 & 17.36 & 15.43 & 13.5 & 11.58 & 9.66 & 7.74 & 5.8 & 3.84 & 1.84 & 1.0 \\
\hline$E_{l}[w \mid i]$ & 19.60 & 17.63 & 15.67 & 13.72 & 11.77 & 9.82 & 7.87 & 5.90 & 3.92 & 1.97 & 1.0 \\
\hline \hline
\end{tabular}


A notable difference between this equilibrium and the previous one is that while the magnitude of the discrimination is much larger in this equilibrium, there is almost no difference in average wages. The average wage of both types is almost exactly 10.00. The reason for this is that quality in both types is identically distributed. This observation emphasizes the fact that average wage differences are a measure of quality differences in the economy, not a measure of the amount of economic discrimination.

Finally, consider the case in which group $h$ quality is distributed Normal[11,2] with $\Delta_{h}=1.00$ and group $l$ quality is distributed Normal[9,2.5] with $\Delta_{l}=1.95$, so type $h$ agents higher average quality as well as lower signal noise. By comparing the fourth row of Table 1 to the fourth row of Table 2 we can get some idea of relative importance of the underlying factors that drive the discrimination, albeit in a slightly different economy in which the supply of jobs is given by the sum of $n_{h}$ in Table 2 and $n_{l}$ in Table 1 . It is clear differences in signal noise are a much more important factor than differences in quality. For example in such an economy group $h$ agents are systematically legally discriminated against - the differences in quality are swamped by the differences in signal noise. As in the uniform example, the group that both is better qualified on average and has lower measurement error will suffer from systematic legal discrimination. Furthermore, from Figure 3, despite the systematic legal discrimination, systematic economic discrimination does not result and the magnitude of this discrimination is of the same order as the case when quality was identically distributed across the two types.

\subsection{Case III: Cauchy Distributed Agents}

In this subsection we will consider an identical job market to Subsection 5.2 except that now agent's qualities are assumed to be distributed under a Cauchy distribution, that is, we assume that

$$
F^{l} \equiv \text { Cauchy[9,2] and } F^{h} \equiv \text { Cauchy[11,2] }
$$

where Cauchy $[a, b]$ is a Cauchy distribution function with location parameter $a$ and scale parameter $b$. These two distributions are plotted as the light curves in Figure 1, Panel A. Agents of type $h$ are therefore "better" in terms of the fact that $F^{h}$ stochastically dominates $F^{l}$. Nevertheless, as Figure 1, Panel B demonstrates the recognize ratio is not monotone over all job sectors. As a result, the direction of the discrimination in equilibrium will not always favor one type. Type $l$ agents will benefit from the discrimination in the best and the worst sectors.

to apply for a job that they are certain to get. 
Figure 4: Percentage Difference in Expected Wages in the Economy with Identical Quality Distributions but Differing Signal Noise

The expected wage of an agent of quality $q$, is the probability of getting the job this agent chooses to apply for multiplied by the wage offered for this job. The percentage difference between the expected wage of two agents of the same quality is then defined to be the expected wage of the agent of type $h$ minus the expected wage of the agent of type $l$ divided by the expected wage of the agent of type $l$ (i.e., $\frac{E_{h}[w \mid q]-E_{l}[w \mid q]}{E_{l}[w \mid q]}$ ) expressed in percentage terms. The dark curve is economy with normally distributed agents and the light curve is the economy with Cauchy distributed agents.

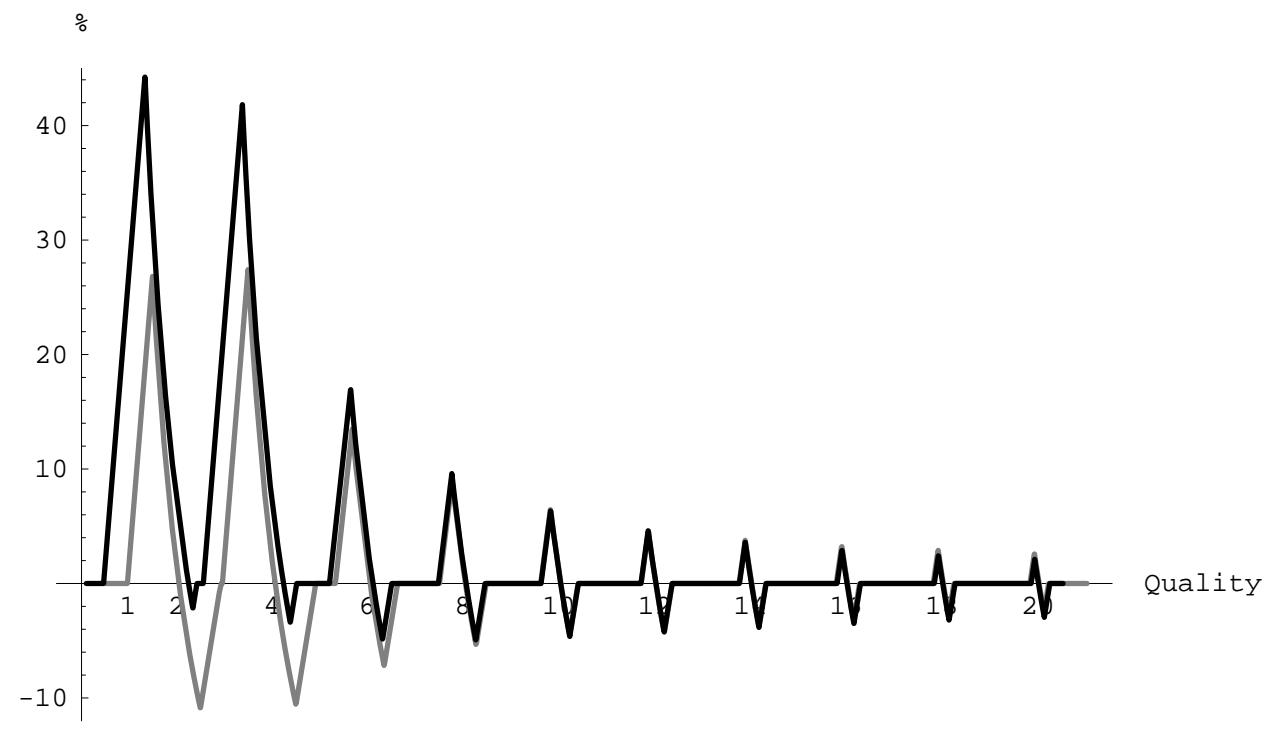


Substituting this distributional assumption into (13) and integrating provides,

$$
\begin{aligned}
\log \left(\frac{85-18\left(s_{l i}^{*}+\Delta_{t} W_{i}\right)+\left(s_{l i}^{*}+\Delta_{t} W_{i}\right)^{2}}{85-18\left(s_{l i}^{*}+\Delta_{t}\right)+\left(s_{l i}^{*}+\Delta_{t}\right)^{2}}\right) \\
\quad+\left(b_{i}-9\right)\left(\arctan \left(\frac{s_{l i}^{*}+\Delta_{t}-9}{2}\right)-\arctan \left(\frac{s_{l i}^{*}+\Delta_{t} W_{i}-9}{2}\right)\right)=0
\end{aligned}
$$

for agents of type $l$ and

$$
\begin{aligned}
& \log \left(\frac{125-22\left(s_{h i}^{*}+\Delta_{t} W_{i}\right)+\left(s_{h i}^{*}+\Delta_{t} W_{i}\right)^{2}}{125-22\left(s_{h i}^{*}+\Delta_{t}\right)+\left(s_{h i}^{*}+\Delta_{t}\right)^{2}}\right) \\
& \quad+\left(b_{i}-11\right)\left(\arctan \left(\frac{s_{h i}^{*}+\Delta_{t}-11}{2}\right)-\arctan \left(\frac{s_{h i}^{*}+\Delta_{t} W_{i}-11}{2}\right)\right)=0
\end{aligned}
$$

for agents of type $h$. The solution to these two equations and equation (12) provides the equilibrium $s_{t i}^{*}$ and $q_{i}^{t}$ for each type $t$ and job $i$ in the economy. $n_{i}$ is then set by solving (8).

Table 3: Equilibrium in the Economy with Cauchy Agents with Identical Signal Noise

Quality (marginal product) is distributed Cauchy[9,2] for agents of type $l$, Cauchy[11,2] for agents of type $h$ and $\Delta_{h}=\Delta_{l}=1.95$. The fraction of employees employed $(n)$, the offered wage or minimal expected marginal product $(w)$, the equilibrium critical signal $\left(s_{h}^{*}\right.$ and $\left.s_{l}^{*}\right)$, the upper bound on quality $\left(\bar{q}^{h}\right.$ and $\left.\bar{q}^{h}\right)$ and the fraction of each type employed in each sector $\left(n_{h}\right.$ and $\left.n_{l}\right)$ are listed below. The final two rows $\left(E_{h}[w \mid i]\right.$ and $\left.E_{l}[w \mid i]\right)$ are the expected wage of all employees of a particular

\begin{tabular}{|c|c|c|c|c|c|c|c|c|c|c|c|}
\hline & \multicolumn{11}{|c|}{ Job } \\
\hline & 1 & 2 & 3 & 4 & 5 & 6 & 7 & 8 & 9 & 10 & res \\
\hline $\bar{n}$ & 6.45 & $\bar{~} 1.63$ & 2.73 & 5.37 & $\begin{array}{l}12.98 \\
\end{array}$ & $\begin{array}{l}24.04 \\
\end{array}$ & 21.22 & 8.95 & $\begin{array}{l}3.57 \\
\end{array}$ & 1.49 & 27.00 \\
\hline$w$ & 20.0 & 18.0 & 16.0 & 14.0 & 12.0 & 10.0 & 8.0 & 6.0 & 4.0 & 2.0 & 1.0 \\
\hline$s_{h}^{*}$ & 18.2477 & 16.271 & 14.301 & 12.340 & 10.389 & 8.420 & 6.501 & 4.652 & 2.942 & 0.9582 & $-\infty$ \\
\hline$s_{l}^{*}$ & 18.2472 & 16.270 & 14.299 & 12.337 & 10.391 & 8.460 & 6.506 & 4.636 & 2.917 & 0.942 & $-\infty$ \\
\hline $\bar{q}^{h}$ & $\infty$ & 19.808 & 17.788 & 15.763 & 13.733 & 11.689 & 9.59 & 7.476 & 5.302 & 2.942 & 0.958 \\
\hline $\bar{q}^{l}$ & $\infty$ & 19.807 & 17.787 & 15.761 & 13.730 & 11.691 & 9.63 & 7.481 & 5.286 & 2.917 & 0.942 \\
\hline$n_{h}$ & 7.09 & 1.98 & 3.46 & 7.25 & 18.62 & 29.18 & 13.47 & 5.25 & 2.47 & 1.15 & 6.26 \\
\hline$n_{l}$ & 5.81 & 1.28 & 1.99 & 3.49 & 7.33 & 18.90 & 28.94 & 12.66 & 4.67 & 1.84 & 7.74 \\
\hline$E_{h}[w \mid i]$ & 19.96 & 17.74 & 15.69 & 13.62 & 11.56 & 9.69 & 7.69 & 5.54 & 3.29 & 1.54 & 1.0 \\
\hline$E_{l}[w \mid i]$ & 19.97 & 17.75 & 15.71 & 13.65 & 11.56 & 9.48 & 7.62 & 5.58 & 3.33 & 1.55 & 1.0 \\
\hline
\end{tabular}
type who choose to apply in the $i^{\text {th }}$ sector. The overall fraction of employees employed $(n)$ and the fraction by type $\left(n_{h}\right.$ and $\left.n_{l}\right)$ are listed in percent. The final column contains these values for the reservation job in the economy.

The equilibrium for the economy when $\Delta_{h}=\Delta_{l}=1.95$ is shown in Table 3 . One 
important difference between this case and the Normal case is that due to the fat tails of the Cauchy distribution, a much greater fraction of employees are employed in the best sector and reservation job than in the previous case. Considering that the difference in location parameters is 2 , it is somewhat surprising that in no case does the difference in the critical signal exceed 0.04. As a result the economic discrimination is minimal (Figure 5, dark curves). The difference in expected wages expressed as a percentage of the expected wage of the agent of type $l$, is plotted as the lighter curve in Figure 3. This difference never exceeds $1.5 \%$. The difference in the average wage of employees that apply to a particular sector never exceeds 0.21 . There is virtually no discrimination in this economy, even though average wages differ by 1.72 - type $h(l)$ agents make 10.07 (8.35) on average. Another measure that is commonly used as a barometer of discrimination in the economy is the ratio of each type working in a sector. So in this case, even though both types make up an equal fraction in the economy, type $h$ employees are more than twice as numerous in the fifth sector while only half as numerous in the seventh sector. What the example emphasizes is that these differences are not driven by discriminatory policies, but rather, by the fact that quality is distributed differently for the two types.

\section{Figure 5: Expected Wages in the Economy with Cauchy Agents}

The expected wage of an agent of quality $q$, is the probability of getting the job this agent chooses to apply for multiplied by the wage offered for this job. The dark curve is the expected wage of both types of agents in the economy with different quality distributions but the same signal noise, i.e., $\Delta_{h}=\Delta_{l}=1.95$. The light curve is the expected wage of an agent of type $h$ when $\Delta_{h}=1.0$. The vertical gray lines mark the offered wage or minimal expected marginal product for each respective job.

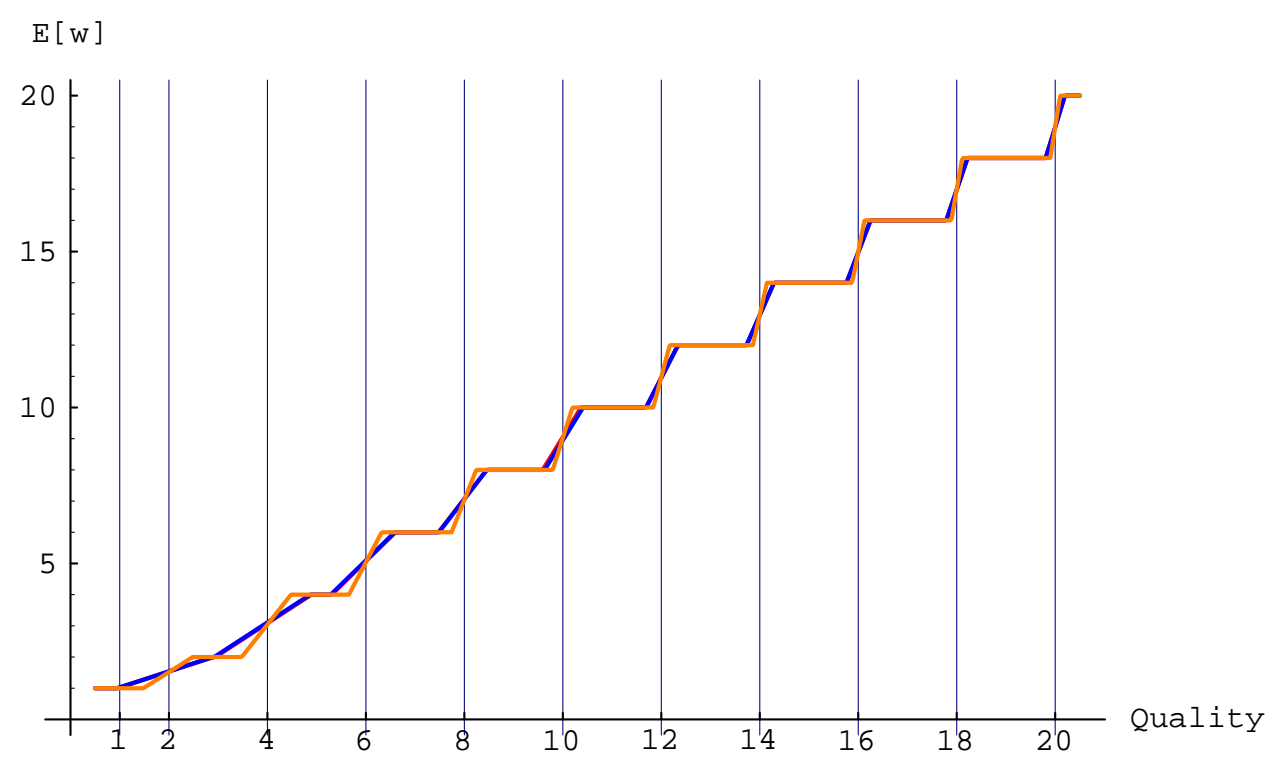


The principle qualitative difference between this example and the Normal example is that the direction of the economic discrimination is different within the range of jobs offered in the economy (see, for instance, Figure 3). In the normal case type $l$ workers are favored in the better sectors, while in the Cauchy case they are favored in the extreme sectors (i.e., the very highly paid and very lowly paid sectors). The principal quantatitive difference is that the magnitude of the discrimination in the Cauchy case is significantly lower than the Normal case (see, for example, Figure 3).

\section{Table 4: Equilibrium in the Economy with Identical Cauchy Agents with Differ- ing Signal Noise}

Quality (marginal product) is distributed Cauchy[11,2] for both types of agents. Agents of type $h$ have higher signal noise than agents of type $l: \Delta_{h}=1.95$ and $\Delta_{l}=1.0$. The fraction of employees employed $(n)$, the offered wage or minimal expected marginal product $(w)$, the equilibrium critical signal $\left(s_{h}^{*}\right.$ and $\left.s_{l}^{*}\right)$, the upper bound on quality $\left(\bar{q}^{h}\right.$ and $\left.\bar{q}^{h}\right)$ and the fraction of each type employed in each sector $\left(n_{h}\right.$ and $\left.n_{l}\right)$ are listed below. The final two rows $\left(E_{h}[w \mid i]\right.$ and $\left.E_{l}[w \mid i]\right)$ are the expected wage of all employees of a particular type who choose to apply in the $i^{\text {th }}$ sector. The overall fraction of employees employed $(n)$ and the fraction by type $\left(n_{h}\right.$ and $\left.n_{l}\right)$ are listed in percent. The final column contains these values for the reservation job in the economy..

\begin{tabular}{|c||c|c|c|c|c|c|c|c|c|c|c||}
\hline \hline \multicolumn{1}{|c||}{} & \multicolumn{1}{c|}{$\begin{array}{c}\text { Job } \\
\end{array}$} & 2 & 3 & 4 & 5 & 6 & 7 & 8 & 9 & 10 & res \\
\hline \hline$n$ & 7.06 & 1.96 & 3.41 & 7.09 & 18.11 & 29.28 & 14.20 & 5.57 & 2.65 & 1.32 & 6.43 \\
\hline$w$ & 20.0 & 18.0 & 16.0 & 14.0 & 12.0 & 10.0 & 8.0 & 6.0 & 4.0 & 2.0 & 1.0 \\
\hline$s_{h}^{*}$ & 18.25 & 16.27 & 14.3 & 12.34 & 10.39 & 8.42 & 6.501 & 4.652 & 2.942 & 0.9582 & $-\infty$ \\
\hline$s_{l}^{*}$ & 19.10 & 17.11 & 15.13 & 13.15 & 11.17 & 9.195 & 7.24 & 5.321 & 3.478 & 1.482 & $-\infty$ \\
\hline $\bar{q}^{h}$ & $\infty$ & 19.81 & 17.79 & 15.76 & 13.73 & 11.69 & 9.59 & 7.476 & 5.302 & 2.942 & 0.9582 \\
\hline $\bar{q}^{l}$ & $\infty$ & 19.9 & 17.89 & 15.88 & 13.86 & 11.84 & 9.795 & 7.74 & 5.654 & 3.478 & 1.482 \\
\hline$n_{h}$ & 7.09 & 1.98 & 3.46 & 7.25 & 18.62 & 29.18 & 13.47 & 5.25 & 2.47 & 1.15 & 6.26 \\
\hline$n_{l}$ & 7.03 & 1.94 & 3.36 & 6.93 & 17.60 & 29.39 & 14.92 & 5.89 & 2.84 & 1.50 & 6.59 \\
\hline$E_{h}[w \mid i]$ & 19.96 & 17.74 & 15.69 & 13.62 & 11.56 & 9.69 & 7.69 & 5.54 & 3.29 & 1.54 & 1.0 \\
\hline$E_{l}[w \mid i]$ & 19.98 & 17.86 & 15.84 & 13.8 & 11.76 & 9.83 & 7.85 & 5.77 & 3.63 & 1.79 & 1.0 \\
\hline \hline
\end{tabular}

The effect of allowing the signal noise distribution to be a function of type is almost identical to that of the economy with normal agents. Table 4 shows the equilibrium of an economy in which quality is distributed identically in the two groups (Cauchy[11,2]) but $\Delta_{h}=1.95$ and $\Delta_{l}=1.0$. The difference in the critical signals, expected wages (Figure 5 ), the percentage difference in the expected wages (Figure 4) and the average wage of employees who apply to a particular sector look much like the normal economy when the signal noise differs. Like the Normal economy average wages are almost identical at 10.07. In contract to the case with identical signal noise, in every sector the ratio of each type working in a sector is very close to the population ratio. Finally, like the uniform and 
normal examples, if the group with the better quality distribution is also endowed with the lower signal noise, then members of this group will by systematically legally discriminated against.

\section{Empirical Implications}

In this section we use the results of two studies (Kuhn (1987) and Neal and Johnson (1996)) to explore the empirical implications of our model. These two studies are chosen for a number of reasons. Firstly, together they span the two main sources of discrimination race and gender. Secondly, both studies use data from time period well after the passage of the civil rights legislation in the early sixties when tastes were the more likely cause of discriminatory practices. Thirdly, Neal and Johnson (1996) make a persuasive case that they are able to accurately measure worker skill level ("quality" in our terminology), while Kuhn (1987) includes a measure of perceived discrimination. Thus the former study allows a test of economic discrimination while the latter allows a test of legal discrimination. Finally, both studies document puzzles which we argue our model might help to explain.

\subsection{Economic Discrimination}

Neal and Johnson (1996) use a data set of workers for which they persuasively argue they can measure both workers' skill levels upon entering the labor force (hereafter "quality") and their subsequent wages. They use as the measure of quality, the Armed Services Vocational Aptitude Battery (ASVAB) which is administered to youths in their sample in 1980 when their ages ranged between 15 and 18. They use the National Longitudinal Surveys of Youth (NLSY) to measure the what these youths actually earned between ten and eleven years later.

Neal and Johnson (1996) find large average quality differences between the three race groups they study (Blacks, Whites and Hispanics). For males, there is one standard deviation between Whites and Blacks and 0.7 standard deviations between Whites and Hispanics. For females these differences are approximately the same. This quality difference is reflected in average wages - equally large differences between the race groups exist there as well. However, once quality is controlled for, these wage differences essentially disappear. The only race/sex group of lower average quality that suffers economic discrimination (wage differences even after quality is controlled for) are Black men when compared to White men. Even here the resulting wage differences are small relative to the overall quality differences as measured by differences in average wages. Perhaps even more interesting is that in a number of cases there is evidence that groups of lower average quality actually earn higher wages when quality is controlled for. In particular, Hispanic women, whose average qual- 
ity is 0.76 standard deviations below White women, actually benefit economically — their wages are statistically significantly greater than White women of the same quality.

The results of this study present a number of empirical puzzles when viewed from the perspective of the literature on statistical discrimination. Firstly, since large differences in quality do exist, one would expect, based on the traditional theory of statistical discrimination, that the statistical inferences employers draw using this fact would result in race discrimination. Yet taken together, Neal and Johnson (1996) find no compelling evidence of this kind of statistical discrimination. Secondly, in some cases they find that the group with the lower average quality benefits economically, something that the authors themselves readily admit defies a good explanation.

Table 5: Theoretical Value of Regression Coefficients: The first four columns give the details of the distribution of quality and signal noise of each type in the economy. $(\mathrm{N}[\mu, \sigma]$ is a Normal distribution with mean $\mu$ and standard deviation $\sigma$.) The fifth column gives the theoretical coefficient (in the true population) of a univariate regression of expected wages on a dummy variable for type $l$. The last two columns are these coefficients for a multiple regression of expected wages on quality and the type $l$ dummy.

\begin{tabular}{|l||l|l|c|c||c||c|c||}
\hline \hline \multicolumn{1}{|c||}{} & \multicolumn{2}{c||}{ Quality Distribution } & \multicolumn{2}{c||}{ Signal Noise } & \multicolumn{2}{c||}{ Univariate } & \multicolumn{2}{c||}{ Multivariate } \\
& $f^{h}$ & $f^{l}$ & $\Delta_{h}$ & $\Delta_{l}$ & Type $l$ & Quality & Type $l$ \\
\hline 1 & $\mathrm{~N}[11,2]$ & $\mathrm{N}[9,2.5]$ & 1.95 & 1.95 & -1.9923 & 0.9838 & -0.0247 \\
2 & $\mathrm{~N}[11,2]$ & $\mathrm{N}[11,2]$ & 1.95 & 1.00 & 0.0033 & 0.9919 & 0.0033 \\
3 & $\mathrm{~N}[11,2]$ & $\mathrm{N}[9,2.5]$ & 1.00 & 1.95 & -1.9889 & 0.9874 & -0.0140 \\
4 & $\mathrm{~N}[9.5,2]$ & $\mathrm{N}[9,2]$ & 0.50 & 1.95 & -0.4915 & 0.9887 & 0.0028 \\
\hline
\end{tabular}

To evaluate whether the findings in Neal and Johnson (1996) are consistent with our model, we calculate what the theoretical regression coefficients are in our model, for the tests Neal and Johnson (1996) performed. The regression coefficients for Case II in the previous section can be found in Table $5 .{ }^{13}$ The first four columns give the details of the distribution of quality and signal noise. The fifth column gives the result of a univariate regression of expected wages on a dummy variable for type $l .{ }^{14}$ The last two columns are the coefficients of a multiple regression on quality and the type $l$ dummy. In all cases, including quality in the regression reduces the magnitude of the coefficient on the type $l$ dummy variable to the point that it is very close to zero. Consistent with what Neal and Johnson (1996) found, the economic discrimination as measured by this variable is so small it is difficult to detect.

\footnotetext{
${ }^{13}$ The regression coefficients do not exist for Case III because first and second moments of a Cauchy distribution do not exist.

${ }^{14}$ Recall that by the rational expectations hypothesis, the average wage for a given quality level must also be the expected wage for a given level of quality.
} 
The first line is the case when the two types have different quality distributions but the same signal noise and is consistent with what Neal and Johnson (1996) found in the case of Black and White males. The univariate regression of average wages on a dummy for type $l$ produces a large negative coefficient reflecting the large quality differences. When quality is included in a multiple regression, the magnitude of this coefficient drops dramatically, although it remains negative, reflecting the fact that type $l$ agents are, on average, discriminated against.

The second line of Table 5 indicates what would result if the same regressions were run in the economy were the types differ in their signal noise, but the quality distributions are identical. There are two interesting features. First, since quality is identically distributed between the two types, controlling for quality does not change the regression coefficient. Secondly, the coefficient is positive, that is, the average wage of type $l$ agents exceeds type $h$ agents, even though type $l$ agents are systematically legally discriminated against.

Because of the relatively large magnitude of the legal discrimination that results from differences in signal noise, the quality distributions can be changed without affecting the sign of this coefficient. The third row of Table 5 shows this. Type $l$ agents have lower average quality and higher signal noise. We demonstrated in the previous section that in this case systematic legal discrimination in favor of type $l$ agents. Yet the regression shows that on average, type $l$ agents are economically discriminated against (lower, quality adjusted, wages).

An interesting feature of the Neal and Johnson (1996) study is that the conditions in Proposition 3 appear to be satisfied for the comparison of all race groups to Whites for each sex. ${ }^{15}$ Thus if quality differences were the only factor, any economic discrimination that is detected should be systematic and favor the better qualified group. Although this factor might explain the small economic discrimination against Black men relative to White men, it is inconsistent with the economic discrimination that favors Hispanic men relative to White men and both Hispanic women and Black women relative to White women. What these results imply is that to be consistent with our model, the groups with lower average quality must also be less familiar. As we show explicitly in the last line of Table 5 it is possible in our model for the lower average quality/less familiar group to have lower average wages and yet have higher quality adjusted wages (positive multiple regression coefficient on the type dummy).

\footnotetext{
${ }^{15}$ The condition is satisfied for the quality histograms (Figures 2 and 3 in that paper) and is also satisfied if the distribution is assumed to be normal with the means and variances reported in Table A1 of that paper.
} 


\subsection{Legal Discrimination}

From our perspective the major advantage of the Neal and Johnson (1996) study is that the data includes a relatively accurate measure of prior skill level. Unfortunately, since the study is restricted to measuring economic discrimination, it has nothing to say about the nature of legal discrimination in the economy. To find empirical evidence about this kind of discrimination we need to turn to a study by Kuhn (1987). Unfortunately, the cost is that, as Neal and Johnson (1996) argue, the skill level controls they use are noisy and any many cases have biases towards overstating the amount of discrimination.

Using the 1977 American Quality of Employment Survey and the 1977 Canadian Quality of Life Survey, Kuhn (1987) estimates the statistical relationship of Whites, by sex, between a number of human capital variables that have been used to proxy for skill level (education, job tenure, age, etc) and the wage earned using ordinary least squares regressions. He then measures the average economic discrimination by calculating the difference between what an average female earned and what she would have earned had she had the male OLS coefficients. What makes this study interesting from our perspective is that both these data sets also include a question asking whether the employee had ever experienced discrimination. The puzzling finding that we will focus on is the following robust yet only marginally significant result - an inverse relation between the amount of measured economic discrimination and the likelihood of a women reporting that she had been discriminated against. In a follow up study Barbezat and Hughes (1990) find similar, although in this case, statistically significant, evidence of this inverse correlation in a completely different sample.

This result, together with Kuhn's explanation, generated a significant level of controversy (see Barbezat and Hughes (1990), Even (1990) and Kuhn (1990)). All of the discussion and alternative explanations of the result have one thing in common. As Kuhn (1990, p. 291) puts it: "any 'explanation' .... will in some way be based on an omitted variable in the regression of reports on measures."

Now a women might report having been discriminated against for a number of reasons. One such reason is if she believes she has been subject to different hiring and promotion criteria, that is, if she suffers from legal discrimination. Another reason for reporting discrimination is if she felt that she earned less than equally qualified men doing the same job. Thus the answer to this question reflects both legal and economic discrimination. Since in our model it is possible for employees to be legally discriminated against but not economically discriminated against (and visa versa) the empirical result that the amount of measured economic discrimination is inversely related to the probability of reporting having suffered from discrimination need not necessarily be inconsistent.

Legal discrimination does not lead to economic discrimination when the discrimination results from differences in familiarity. In this case, legal discrimination against the more 
familiar group results, but this group does not always earn lower quality adjusted wages. A person from the more familiar group might honestly report suffering from (legal) discrimination, yet have a higher quality adjusted wage. As we have already pointed out, this is precisely what happens in the second and third rows of Table 5. In both cases we explicitly demonstrate in the previous section that the legal discrimination is systematic, it is relatively large in magnitude and it favors the less familiar group (type $h$ in the second row and type $l$ in the third row). Yet the average quality adjusted wage is lower for this group. Both of these rows are consistent with what Kuhn (1987) found - the benefit derived from the relatively large legal discrimination could bias members of the less familiar group to not report having suffered from discrimination even though their quality adjusted wages are lower.

The stated objective of Kuhn's original article was to evaluate the admissibility of economic discrimination as evidence of discrimination in a court of law (i.e., legal discrimination). In Bazemore et al v. William Friday et al. (1986) the U.S. Supreme Court ruled that regression analysis documenting pay differentials could not be dismissed simply because the possibility that omitted variables might exist. This paper shows that except in the case when the discrimination results purely from particular differences in the distribution of quality, evidence of economic discrimination is not sufficient to conclude legal discrimination exists. This result suggests that the admissibility of this evidence should not simply be determined by the likelihood of omitted variables. The issue might have more to do with the factors responsible for the discrimination as well the characteristics of the distribution of quality in the population.

\section{Conclusion}

In most democracies it is generally accepted that discrimination, like slavery, is morally wrong. Unlike slavery, it was widely perceived until recently that discrimination continued to exist. Governments of these democracies saw themselves as having an important role in eliminating the practice.

The analysis in this paper is restricted to only statistical discrimination. It does not examine taste-based discrimination. We would argue that anti-discrimination law was originally designed to eliminate taste-based discrimination, not necessarily statistical discrimination. In light of this, it is interesting to consider what effect these laws might have on employers who do not have a taste for discrimination but nevertheless statistically discriminate.

Consider, first, an economy in which legal discrimination results only from employers' differing abilities to access quality in different population groups. In this case a law outlawing legal discrimination could actually disadvantage the less familiar type. By not allowing 
employers to use factors such as race in their decisions, they would not be able to compensate for their own inability to measure quality in the unfamiliar group. The net result would be that the more familiar group members would get better jobs than they otherwise would have gotten. As more members of this group are hired, overall employer familiarity with this group is likely to rise at the expense of the other group, resulting in the kind of feedback mechanism that Cornell and Welch (1996) show can lead to only members of the familiar group being hired.

The effect of quota type laws can also yield socially undesirable results. Take, for example, the economy in Section 5.3 when $\Delta_{h}=\Delta_{l}$. Although there is almost no economic discrimination in this economy (expected wages differ by no more than 1.5\%), the fraction of applicants that are ultimately hired from each group differs dramatically across jobs (see Table 3). Employers offering lower skilled jobs hire relatively more workers of type $l$ than employers offering higher skilled jobs do. Thus overall average wages differ dramatically between the two population types. Suppose a government, upon observing this, concluded that significant economic discrimination existed and passed a quota law requiring all employers to hire employees of a particular type in the same fraction as they are represented in the population. In order to comply, the higher skilled employers, who are actually discriminating against the "better" type in this example, would be forced to drop their standards significantly. This dramatically reduces the average qualifications of their type $l$ employees, presumably adversely affecting productivity. One might still argue that this productivity loss is a necessary cost to eliminate discrimination in the economy, however, it is important to keep in mind that the amount of both legal and economic discrimination was minimal to begin with.

There is also the question of how to enforce current anti-discrimination law. It is very difficult to determine empirically whether an employer does use race or sex in the hiring decision. One criterion that is sometimes used is the fraction of a population group hired to the group's fraction of the overall population. The problems with such a policy are best illustrated in the high skill sectors of the economies in Sections 5.2 and 5.3 when $\Delta_{h}=\Delta_{l}$. In these sectors type $h$ agents are both economically and legally discriminated against. However, as there are far fewer type $l$ agents who meet the quality standards for these jobs, the fraction of these agents who are employed in these sectors is much lower than their overall fraction in the population. Paradoxically, it is the under-represented type that benefits from the discrimination.

Another criterion that has been used as evidence of discrimination is regression analysis that controls for skill differences. Even if the issues with finding accurate measures of employee skills are set aside, at best, this kind of analysis can only provide evidence of economic discrimination. The problem is that the existence economic discrimination does 
not necessarily imply the existence of legal discrimination. This result is arguably the most significant from a policy perspective because it questions current legal precedents that implicitly accept economic discrimination as evidence of legal discrimination.

The object of the anti-discrimination laws that were passed in the early sixties was to eliminate what, at the time, was widely recognize to be taste-based discrimination. Empirically, there is strong evidence (e.g., Neal and Johnson (1996)) that the legislation has been successful and so one might well argue that current discrimination is no longer primarily taste based. If this true, the results in this paper show that it might be worth studying whether these laws (and the legal precedents built around them) continue to serve the original objective of eliminating discrimination in the economy. 


\section{Appendix}

\section{A Logconcavity}

Let $G(x)$ be a distribution function with associated density function $g(x)$. Define $h(x) \equiv$ $\frac{g(x)}{1-G(x)}$ (the hazard rate).

Lemma A.1 If $g(x)$ is a twice differentiable and logconcave density function then for any $d>0, h(x)$ and $\left(\frac{1-G(x)}{1-G(x+d)}\right)$ are both non-decreasing and $\frac{g^{\prime}(x)}{g(x)}$ is non-increasing.

Proof: The proof that $h(x)$ is non-decreasing is well known (see An (1998)). The fact that $\frac{g^{\prime}(x)}{g(x)}$ is non-increasing follows immediately from Lemma 2 in An (1998). Finally note that

$$
\frac{d}{d x}\left(\frac{1-G(x)}{1-G(x+d)}\right)=\left(\frac{1-G(x)}{1-G(x+d)}\right)(h(x+d)-h(x))
$$

so this ratio is non-decreasing because $h(x)$ is non-decreasing.

\section{B Lemmas}

Lemma B.1 Holding wages fixed, for any $s_{t i}^{*}$ and $\bar{q}_{i+1}^{t}$ that satisfy equation (10),

$$
\begin{aligned}
& \text { (i) } \frac{d \bar{q}_{i+1}^{t}}{d s_{i}^{*}}=1 \\
& \text { (ii) } \frac{d B_{t}\left(s_{t i}^{*}, \bar{q}_{i+1}^{t}, s_{t i}^{*}+\Delta\right)}{d s_{t i}^{*}}>0
\end{aligned}
$$

Proof: We will again suppress the type subscript. Taking the derivative of (10) w.r.t. $s_{i}^{*}$ provides,

$$
\begin{aligned}
& w_{i} g\left(s_{i}^{*}-\bar{q}_{i+1}\right)\left(1-\frac{d \bar{q}_{i+1}}{d s_{i}^{*}}\right)=0 \\
\Rightarrow & \frac{d \bar{q}_{i+1}}{d s_{i}^{*}}=1
\end{aligned}
$$

Taking the derivative of $B\left(s_{i}^{*}, \bar{q}_{i+1}, s_{i}^{*}+\Delta\right)$ using (i) provides,

$$
\frac{d B\left(s_{i}^{*}, \bar{q}_{i+1}, s_{i}^{*}+\Delta\right)}{d s_{i}^{*}}=B_{1}\left(s_{i}^{*}, \bar{q}_{i+1}, s_{i}^{*}+\Delta\right)+
$$




$$
\begin{array}{rl}
\quad \frac{\left[\bar{q}_{i}-B\left(s_{i}^{*}, \bar{q}_{i+1}, s_{i}^{*}+\Delta\right)\right] g(-\Delta) f\left(s_{i}^{*}+\Delta\right)+\left[B\left(s_{i}^{*}, \bar{q}_{i+1}, \bar{q}_{i}\right)-\bar{q}_{i+1}\right] g\left(s_{i}^{*}-\bar{q}_{i+1}\right) f\left(\bar{q}_{i+1}\right)}{\int_{\bar{q}_{i+1}} g\left(s_{i}^{*}-u\right) d F(u)} \\
>0 & 0
\end{array}
$$

because, by Lemma 3.1, the first term is non-negative and the second term is strictly positive ( $B_{1}$ denotes the partial derivative w.r.t. the first argument)

Lemma B.2 In equilibrium, for each type $t \in\{h, l\}$ and every $i=1 \ldots I, \bar{q}_{i}^{t}-\Delta_{t}>s_{t i}^{*}$.

Proof: Take an equilibrium $\left\{w_{i},\left\{\bar{q}_{i}^{t}, s_{t i}^{*}\right\}_{t=l, h}\right\}_{i=1}^{I}$ of the economy and assume the opposite - assume that $\bar{q}_{i}^{t}-\Delta_{t} \leq s_{t i}^{*}$. Now consider the inference made by an employer, in sector $i$, upon seeing, from an applicant of type $t$, a signal realization $s \in\left[\bar{q}_{i}^{t}-\Delta_{t}, \bar{q}_{i+1}^{t}+\Delta_{t}\right]$. Using the assumption that $\delta$ is Uniform $\left[-\Delta_{t}, \Delta_{t}\right],(1)$ becomes,

$$
B_{t}\left(s, q_{i+1}^{t}, \bar{q}_{i}^{t}\right)=\left(\frac{1}{\int_{\bar{q}_{i+1}^{t}}^{\bar{q}_{i}^{t}} d F^{t}(u)}\right) \int_{\bar{q}_{i+1}^{t}}^{\bar{q}_{i}^{t}} u d F^{t}(u) .
$$

because by the assumption and Lemma 3.3, the inferred quality cannot lie outside the support of the quality distribution. Note that (21) does not depend on the signal realization, so the employer infers the same quality for any $s \in\left[\bar{q}_{i}^{t}-\Delta_{t}, \bar{q}_{i+1}^{t}+\Delta_{t}\right]$. Since $s_{t i}^{*} \in\left[\bar{q}_{i}^{t}-\Delta_{t}, \bar{q}_{i+1}^{t}+\Delta_{t}\right)$, the $i^{t h}$ employer infers the same expected quality for signals $s_{t i}^{*}$ and $\bar{q}_{i+1}^{t}+\Delta_{t}$. However since $\bar{q}_{i+1}^{t}+\Delta_{t}>s_{t i}^{*}$ this implies that $s_{t i}^{*}$ is not the critical signal which is a contradiction.

Lemma B.3 Suppose $g^{t} \sim$ Uniform $\left[-\Delta_{t}, \Delta_{t}\right]$. If wages are held fixed, then for any sector $i$ such that $\frac{w_{i}}{w_{i+1}} \leq 2$,

$$
\begin{aligned}
& \text { 1. }-1<\frac{\partial s_{t i}^{*}}{\partial \Delta_{t}}<0 \text {, and } \\
& \text { 2. }-1<\frac{\partial \bar{q}_{i+1}^{t}}{\partial \Delta_{t}}<0 \text {. }
\end{aligned}
$$

Proof: 1 . The equilibrium sensitivity of the critical signal $s_{t i}^{*}$ to the level of noise, $\Delta_{t}$ can be determined by differentiating (13) providing:

$$
\frac{\partial s_{t i}^{*}}{\partial \Delta_{t}}=-\left(\frac{W_{i}-X}{1-X}\right)
$$

where

$$
X=\frac{\left(s_{t i}^{*}+\Delta_{t}-b_{i}\right) f^{t}\left(s_{t i}^{*}+\Delta_{t}\right)}{\left(s_{t i}^{*}+W_{i} \Delta_{t}-b_{i}\right) f^{t}\left(s_{t i}^{*}+W_{i} \Delta_{t}\right)}
$$


Note that by the definition of the critical signal $s_{t i}^{*}$, at least one agent whose true quality exceeds $b_{i}$ and who can realize $s_{t i}^{*}$ must exist, i.e., $s_{t i}^{*}+\Delta_{t}>b_{i}$. Furthermore, from (12), we have that $\left(s_{t i}^{*}+W_{i} \Delta_{t}-b_{i}\right)<0$. Thus $X<0$ and $\frac{w_{i}}{w_{i+1}} \leq 2$ implies that $W_{i} \geq 0$, so $\frac{\partial s_{t i}^{*}}{\partial \Delta_{t}}<0$. Noting that $W_{i}<1$ provides $\frac{\partial s_{t i}^{*}}{\partial \Delta_{t}}>-1$.

2. Differentiating (12) and then substituting in (22) gives:

$$
\begin{aligned}
\frac{\partial \bar{q}_{i+1}^{t}}{\partial \Delta_{t}} & =\frac{\partial s_{t i}^{*}}{\partial \Delta_{t}}+W_{i} \\
& =-\left(\frac{W_{i}-X}{1-X}\right)+W_{i} \\
& =-\left(\frac{-X}{1-X}\right)\left(1-W_{i}\right) .
\end{aligned}
$$

The result follows by using the fact that $0 \leq W_{i}<1$ and $X<0$.

\section{Proofs}

PROOF Of LEMMA 3.1: For convenience, the type superscript will be suppressed. Differentiating (1) (holding $a$ and $b$ fixed) provides:

$$
\frac{\partial B(s, a, b)}{\partial s}=\frac{\int_{a}^{b} u g^{\prime}(s-u) d F(u)-B(s, a, b) \int_{a}^{b} g^{\prime}(s-u) d F(u)}{\int_{a}^{b} g(s-u) d F(u)}
$$

For this expression to be non-negative, the numerator must be non-negative. That is, we need to show that

$$
\int_{a}^{b} u g^{\prime}(s-u) d F(u) \geq B(s, a, b) \int_{a}^{b} g^{\prime}(s-u) d F(u) B(s, a, b) .
$$

Note that from the definition of $B(s, a, b)$, (i.e., (1)) we have

$$
\int_{a}^{b}(u-B(s, a, b)) g(s-u) d H(u ; s, a, b)=0 .
$$

From the fact that $g(x)$ is logconcave, by Lemma A.1 $\frac{g^{\prime}(s-u)}{g(s-u)}$ is non-decreasing for any $u \in[a, b)$. This together with (25) implies

$$
\begin{aligned}
\int_{a}^{b}(u-B(s, a, b)) \frac{g^{\prime}(s-u)}{g(s-u)} g(s-u) d H(u ; s, a, b) & \geq 0 \\
\Rightarrow \int_{a}^{b} u \frac{g^{\prime}(s-u)}{g(s-u)} g(s-u) d H(u ; s, a, b) & \geq B(s, a, b) \int_{a}^{b} \frac{g^{\prime}(s-u)}{g(s-u)} g(s-u) d H(u ; s, a, b)
\end{aligned}
$$




$$
\Rightarrow \int_{a}^{b} u g^{\prime}(s-u) d F(u) \geq B(s, a, b) \int_{a}^{b} g^{\prime}(s-u) d F(u)
$$

PROOF OF LEMMA 3.2: We assume the opposite and derive a contradiction. Assume that for some $j>i$ there exist agents $a$ and $b$ of the same type with qualities $q_{a}>q_{b}$ such that $a$ applies for job $j$ and $b$ applies for job $i$. This implies that,

$$
\begin{aligned}
& w_{j} P_{t}\left(q_{a}, j\right)>w_{i} P_{t}\left(q_{a}, i\right) \\
& w_{j} P_{t}\left(q_{b}, j\right) \leq w_{i} P_{t}\left(q_{b}, i\right),
\end{aligned}
$$

so

$$
\frac{P_{t}\left(q_{a}, j\right)}{P_{t}\left(q_{a}, i\right)}>\frac{P_{t}\left(q_{b}, j\right)}{P_{t}\left(q_{b}, i\right)}
$$

Now, substituting (2) into (26) provides,

$$
\frac{1-G^{t}\left(s_{t j}^{*}-q_{a}\right)}{1-G^{t}\left(s_{t i}^{*}-q_{a}\right)}>\frac{1-G^{t}\left(s_{t j}^{*}-q_{b}\right)}{1-G^{t}\left(s_{t i}^{*}-q_{b}\right)} .
$$

Since $q_{a}>q_{b},(27)$ implies that the function $\frac{1-G^{t}(x)}{1-G^{t}(x+d)}$, where $d>0$, is strictly decreasing at some point. But by Lemma A.1 this contradicts the assumption that the hazard function is increasing everywhere.

PROOF OF PROPOSITION 1: Take an equilibrium $\left\{w_{i},\left\{\bar{q}_{i}^{t}, s_{t i}^{*}\right\}_{t=l, h}\right\}_{i=1}^{I}$ of the economy. Using (9), the critical signal for agents of type $l$ solves

$$
\int_{\bar{q}_{i+1}^{l}}^{s_{l i}^{*}+\Delta}\left(u-b_{i}\right) g\left(s_{l i}^{*}-u\right) d F^{l}(u)=0,
$$

in each sector $i$. When $\frac{f^{h}}{f^{l}}$ is strictly increasing on $\left[\bar{q}_{i+1}^{t}, s_{l i}^{*}+\Delta\right] \subset\left[b_{i+1}, b_{i-1}\right]$, we have that,

$$
\begin{aligned}
0 & <\int_{\bar{q}_{i+1}^{l}}^{s_{l i}^{*}+\Delta}\left(u-b_{i}\right) g\left(s_{l i}^{*}-u\right) \frac{f^{h}}{f^{l}} d F^{l}(u) \\
& =\int_{\bar{q}_{i+1}^{l}}^{s_{l i}^{*}+\Delta}\left(u-b_{i}\right) g\left(s_{l i}^{*}-u\right) d F^{h}(u) .
\end{aligned}
$$


Rearranging terms,

$$
b_{i}<\frac{\int_{\bar{q}_{i+1}^{l}}^{s_{l i}^{*}+\Delta} u g\left(s_{l i}^{*}-u\right) d F^{h}(u)}{\int_{\bar{q}_{i+1}^{l}}^{s_{l i}^{*}+\Delta} g(s-u) d F^{h}(u)}=B_{h}\left(s_{l i}^{*}, \bar{q}_{i+1}^{l}, s_{l i}^{*}+\Delta\right)
$$

Now, by $(3), B_{h}\left(s_{h i}^{*}, \bar{q}_{i+1}^{h}, s_{h i}^{*}+\Delta\right)=b_{i}$, so by condition (ii) of Lemma B.1, $s_{h i}^{*}<s_{l i}^{*}$. This implies that $\bar{q}_{i+1}^{h}<\bar{q}_{i+1}^{l}$ by condition (i) of the same lemma.

PROOF OF PROPOSITION 2: Since both groups have identical signal noise, $s_{l i}^{*} \geq s_{h i}^{*}$ implies that for every $q<s_{l i}^{*}+\Delta, P_{h}(q, i)>P_{l}(q, i)$. Thus, so long as both candidates choose to apply for the same job, the expected wage of the type $h$ candidate can be no smaller than the expected wage of the type $l$ candidate.

By the revealed preference argument, if a candidate of type $h$ and quality $q \in\left(\bar{q}_{i+1}^{h}, s_{l i}^{*}+\right.$ $\Delta)$ chooses to apply for job $i-1$ then $w_{i-1} P_{h}(q, i-1) \geq w_{i} P_{h}(q, i)$. Since $w_{i} P_{h}(q, i) \geq$ $w_{i} P_{l}(q, i)$, we have that $w_{i-1} P_{h}(q, i-1) \geq w_{i} P_{l}(q, i)$. Similarly, if a candidate of type $l$ and quality $q \in\left(\bar{q}_{i+1}^{h}, s_{l i}^{*}+\Delta\right)$ chooses to apply for job $i+1$ then his expected wage is $w_{i+1} P_{l}(q, i+1) \leq w_{i+1}$. However, by revealed preferences $w_{i+1}<w_{i} P_{h}(q, i)$, so $w_{i+1} P_{l}(q, i+$ $1)<w_{i} P_{h}(q, i)$, and so the proposition also holds when the candidates apply for different jobs.

PROOF OF PROPOSITION 3: Systematic legal discrimination follows immediately from Proposition 1. Proposition 2 guarantees that for each sector $i$, type $l$ agents with quality between $\bar{q}_{i+1}^{h}$ and $s_{l i}^{*}+\Delta$ suffer economic discrimination. Since all other agents apply for jobs that they can get for sure, their expected wage is just the wage in the sector that they choose to apply. Furthermore, agents of the same quality apply for the same job, regardless of their type. Thus these agents with the same quality earn the same wage which proves the result.

PROOF OF PROPOSITION 4: Take an equilibrium $\left\{w_{i},\left\{\bar{q}_{i}^{t}, s_{t i}^{*}\right\}_{t=l, h}\right\}_{i=1}^{I}$ of the economy. Note that by (10)

$$
\frac{1}{2} \leq \frac{w_{i+1}}{w_{i}}=\left(1-G^{t}\left(s_{t i}^{*}-\bar{q}_{i+1}^{t}\right)\right)
$$

which implies that $\bar{q}_{i+1}^{t} \geq s_{t i}^{*}$ for $t=l, h$ by the symmetry of $g^{t}(\cdot)$. Thus, for any $q>\bar{q}_{i+1}^{t}$,

$$
s_{t i}^{*}-q<0
$$

The rest of the proof follows the same logic as the proof of Proposition 1. Using (9), in 
equilibrium the $i^{\text {th }}$ employer will set the critical signal for agents of type $l$ such that

$$
\int_{\bar{q}_{i+1}^{l}}^{s_{l i}^{*}+\Delta_{l}}\left(u-b_{i}\right) g^{l}\left(s_{l i}^{*}-u\right) d F(u)=0 .
$$

By $(28)$ and the fact that type $h$ agents are less familiar, $\frac{g^{h}\left(s_{l i}^{*}-q\right)}{g^{l}\left(s_{l i}^{*}-q\right)}$ is strictly increasing for $q \in\left(\bar{q}_{i+1}^{t}, s_{h i}^{*}+\Delta_{h}\right)$. We therefore have that,

$$
\begin{aligned}
0 & <\int_{\bar{q}_{i+1}^{l}}^{s_{l i}^{*}+\Delta_{l}}\left(u-b_{i}\right) g^{l}\left(s_{l i}^{*}-u\right) \frac{g^{h}\left(s_{l i}^{*}-u\right)}{g^{l}\left(s_{l i}^{*}-u\right)} d F(u) \\
& \leq \int_{\bar{q}_{i+1}^{l}}^{s_{l i}^{*}+\Delta_{h}}\left(u-b_{i}\right) g^{h}\left(s_{l i}^{*}-u\right) d F(u),
\end{aligned}
$$

where the second inequality follows from the fact that $\Delta_{l} \leq \Delta_{h}$ and $s_{l i}^{*}+\Delta_{l} \geq b_{i}$. Now define a $q$ such that

$$
\frac{w_{i+1}}{w_{i}}=\left(1-G^{h}\left(s_{l i}^{*}-q\right)\right) .
$$

Note that $q>\bar{q}_{i+1}^{l}$ because $G^{h}$ is less familiar than $G^{l}$,

$$
\frac{w_{i+1}}{w_{i}}=\left(1-G^{l}\left(s_{l i}^{*}-q_{i+1}^{l}\right)\right)>\left(1-G^{h}\left(s_{l i}^{*}-q_{i+1}^{l}\right)\right),
$$

and $G^{h}$ is an increasing function. Thus, so long as $q \leq b_{i}$, from (29) we have,

$$
0<\int_{\bar{q}_{i+1}^{l}}^{s_{l i}^{*}+\Delta_{h}}\left(u-b_{i}\right) g^{h}\left(s_{l i}^{*}-u\right) d F(u) \leq \int_{q}^{s_{l i}^{*}+\Delta_{h}}\left(u-b_{i}\right) g^{h}\left(s_{l i}^{*}-u\right) d F(u) .
$$

If $q>b_{i}$ the above inequality holds trivially. inferences terms,

$$
b_{i}<\frac{\int_{q}^{s_{l i}^{*}+\Delta_{h}} u g^{h}\left(s_{l i}^{*}-u\right) d F(u)}{\int_{q}^{s_{l i}^{*}+\Delta_{h}} g^{h}(s-u) d F(u)}=B_{h}\left(s_{l i}^{*}, q, s_{l i}^{*}+\Delta_{h}\right)
$$

Now, in equilibrium $B_{h}\left(s_{h i}^{*}, \bar{q}_{i+1}^{h}, s_{h i}^{*}+\Delta_{h}\right)=b_{i}$, so by condition (ii) of Lemma B.1, $s_{h i}^{*}<s_{l i}^{*}$.

PROOF OF PROPOSITION 6: Take an equilibrium $\left\{w_{i},\left\{\bar{q}_{i}^{t}, s_{t i}^{*}\right\}_{t=l, h}\right\}_{i=1}^{I}$ of the economy. Consider holding wages fixed and introducing a third type of agent to this economy. These new agents have a quality distribution given by $F^{h}$ and a signal noise distribution given by $G^{l}$. Let $\hat{s}_{i}$ and $\hat{q}_{i}+1, i=1, \ldots, I$ be the critical signals and quality bounds that simultaneously satisfy (9) and (10) for these agents. By Proposition $1 \hat{s}_{i}<s_{l i}^{*}$ and by Proposition $4, s_{h i}^{*}<\hat{s}_{i}$, so $s_{l i}^{*}>s_{h i}^{*}$.

PROOF OF PROPOSITION 8: Pick any $i>1$ and consider applicants of quality $q=\bar{q}_{i}^{l}$. 
By Lemma B.3, $\Delta_{h}>\Delta_{l} \Rightarrow \bar{q}_{i}^{l}>\bar{q}_{i}^{h}$. Thus an applicant of quality q and type $h$ applies for job $i-1$ and has expected wage $w_{i-1} P_{h}(q, i-1)$. By the revealed preference argument, $w_{i-1} P_{h}(q, i-1)>w_{i} P_{h}(q, i)$. However, $P_{h}(q, i)=P_{l}(q, i)=1$, so $w_{i} P_{h}(q, i)=w_{i} P_{l}(q, i)$. Putting the two relations together provides $w_{i-1} P_{h}(q, i-1)>w_{i} P_{l}(q, i)$, so for quality level $\bar{q}_{i}^{l}$, employees of type $h$ have higher expected wages than employees of type $l$.

Now consider, for any $i$, applicants of quality $q$, such that $q=s_{l i}^{*}+\Delta_{l}$. Note that by Lemma B.2 an applicant of type $l$ with quality $q$ must apply for the $i^{\text {th }}$ job and $P_{l}(q, i)=1$ so her expected wage is $w_{i}$. However, for applicant of quality $q$ but of type $h, P_{h}(q, i)<1$. To see why note that,

$$
\Delta_{h}=\Delta_{l}+\left(\Delta_{h}-\Delta_{l}\right)>\Delta_{l}+\left(s_{l i}^{*}-s_{h i}^{*}\right),
$$

where the inequality follows from condition (1) in Lemma B.3. Rearranging terms provides,

$$
q=s_{l i}^{*}+\Delta_{l}<s_{h i}^{*}+\Delta_{h}
$$

so $P_{h}(q, i)<1$. Thus $P_{h}(q, i) w_{i}<w_{i}$, so the expected wage of a person of quality $q$ and type $l$ exceeds that of a person of quality $q$ and type $h$. 


\section{References}

Aigner, D.J. and G. Cain (1977), "Statistical Theories of Discrimination in Labor Markers," Industrial and Labor Relations Review, 30, 175-87.

An, Mark Y. (1998), "Logconcavity versus Logconvexity: A Complete Characterization," Journal of Economic Theory, 80, 350-369.

Akerlof, G. (1976), "The Economics of Caste and of the Rat Race and Other Woeful Tales," Quarterly Journal of Economics, 90, 599-617.

Akerlof, G. (1980), "A Theory of Social Custom, of Which Unemployment May Be One Consequence," Quarterly Journal of Economics, 94, 749-75.

Arrow, K. (1972), "Models of Job Discrimination," and "Some Models of Race in the Labor Market," in A.H. Pascal, ed., Racial Discrimination in Economic Life, D.C. Heath, Lexington, MA.

Arrow, K. (1973), "The Theory of Discrimination," in O. Ashenfelter and A. Rees, eds., Discrimination in Labor Markets, Princeton University Press, Princeton, NJ.

Bagnoli, M. and T. Bergstrom (1989), "Log-Concave Probability and Its Application," Manuscript, University of Michigan.

Barbezat, Debra A. and James W. Hughes (1990), "Sex Discrimination in Labor Markets: The Role of Statistical Evidence: Comment," American Economic Review, 80(1), $277-286$.

Becker, G. S., (1971), The Economics of Discrimination, 2nd ed., University of Chicago Press, Chicago.

Berk, Jonathan B., (1998), World Wide Web page: http://haas.berkeley.edu/ berk

Cain, Glen (1986), "The Economic Analysis of Labor Market Discrimination: A Survey," In Handbook of Labor Economics, vol. 1, edited by Orley Ashenfelter and Richard Layard, Amsterdam: North Holland

Cornell B., and I. Welch (1996), "Culture, Information and Screening Discrimination," Journal of Political Economy, 104, 542-71.

Curtright, Phillip (1973), "Achievement, Mobility and the Draft: Their Impact on the Earnings of Men," Social Security Staff Paper, 14, Washington: Government Printing Office. 
Even, William E., (1990), "Sex Discrimination in Labor Markets: The Role of Statistical Evidence: Comment," American Economic Review, 80(1), 287-289.

Griliches, Z., B. Hall and J. Hausman (1978), "Missing Data and Self-Selection in Large Panels," Annales de L'insee, 31-2, 137-76.

Lang, K. (1986), "A Language Theory of Discrimination," Quarterly Journal of Economics, May, 363-82.

Kuhn, Peter (1987), "Sex Discrimination in Labor Markets: The Role of Statistical Evidence," American Economic Review, 77(4), 567-583.

Kuhn, Peter (1990), "Sex Discrimination in Labor Markets: The Role of Statistical Evidence: Reply," American Economic Review, 80(1), 290-297.

Lippman, S.A. and J.J. McCall (1976), "The Economics of Job Search: A Survey, Part 1: Optimal Job Search Policies," Economic Inquiry, 14, 155-189 .

Lundberg, S. J. and R. Startz (1983), "Private Discrimination and Social Intervention in Competitive Labor Markets," American Economic Review, 73, 340-7.

Maxpherson, David A. and Barry. T. Hirsch (1995), "Wages and Gender Composition: Why Do Women's Jobs Pay Less?," Journal of Labor Economics, 13, 426-71.

McCall, J. J., (1973), Income Mobility, Racial Discrimination and Economic Growth, Lexington Heath.

Mortensen, D.T., (1973), "Job Matching Under Imperfect Information," unpublished paper, Northwestern University.

Neal, Derek A. and William R. Johnson (1996), "The Role of Premarket Factors in BlackWhite Wage Differences," Journal of Political Economy, 104(5), 869-895.

Oaxaca, Ronald L. (October 1973), "Male-Female Wage Differentials in Urban Labor Markets" International Economic Review, 14, 693-709.

Oaxaca, Ronald L. and Michael R. Ransom (March 1994), "On Discrimination and the Decomposition of Wage Differentials," Journal of Econometrics, 61, 5-21.

O'Neill, June (Fall 1990), "The Role of Human Capital in Earnings Differences between Black and White Men," Journal of Economic Perspectives, 4, 25-45.

Phelps, E.S., (1972), "The Statistical Theory of Racism and Sexism," American Economic Review, 62, 659-61. 
Reder. M.W. (1972), "Human Capital and Economic Discrimination," in I. Berg, ed., Human Recources and Economic Welfare; Essays in Honor of Eli Ginzberg, Columbia University Press, NY.

Sorensen, Elaine. (Winter 1990), "The Crowding Hypothesis and Comparable Worth Issue: A Survey and New Results," Journal of Human Resources, 25, 55-89.

Spence, A.M. (1973), "Job Market Signalling," Quarterly Journal of Economics, 87, 355-74.

Teulings, C.N. (1995), "The Wage Distribution in a Model of the Assingment of Skills to Jobs," Journal of Political Economy, 103, 280-315.

Welch, F. (1981), "Affirmative Action and Its Enforcement," American Economic Review, 71, 127-33. 